\title{
The Housing Cycle: What Role for Mortgage Market Development and Housing Finance?
}

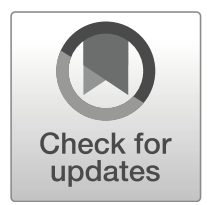

\author{
Luca Agnello ${ }^{1}$. Vitor Castro ${ }^{2,3}$ (1) $\cdot$ Ricardo M. Sousa ${ }^{4,5}$
}

Published online: 15 June 2019

(C) The Author(s) 2019

\begin{abstract}
We use duration analysis to assess the impact of securitization, mortgage sector liberalization and government involvement in housing finance on the length of housing booms, busts and normal times in a panel of 20 OECD countries over the period 1970Q1-2015Q4. Our results reveal that a move towards a more liberalized mortgage sector is associated with longer housing booms, while an increase in securitization is linked with shorter housing busts. They also show that the length of housing booms and busts is particularly sensitive to housing finance characteristics, but that does not seem to be the case for normal times. Additionally, government support measures do not necessarily cushion against housing busts. A careful assessment of their distributional impact, as well as their effect on the trade-off between liquidity and guarantee/loan provision, is also required to prevent (longer) housing booms. All in all, housing finance regulation may prove especially relevant to shield against the damaging effects of housing busts and the financial stability risks associated with housing booms. Monetary policy can also be an important complement to macro-prudential policies. Finally, government participation in housing finance should be designed in a way that avoids an undesirable amplification of house price fluctuations.
\end{abstract}

Keywords Housing booms and busts · Duration analysis · Securitization · Housing finance characteristics · Government participation

JEL Classification C41 $\cdot$ E32 $\cdot$ E51 $\cdot$ E52

NIPE's work is financed by National Funds of the FCT - Portuguese Foundation for Science and Technology within the project "UID/ECO/03182/2019".

Vitor Castro

V.M.Q.Castro@1boro.ac.uk

Extended author information available on the last page of the article. 
“... This boom-bust cycle is commonly seen as a major contributor to the global financial crisis, itself generally recognized as the most dangerous economic threat the world has faced since the Great Depression..."

- Prakash Loungani (2010a, p.16).

\section{Introduction}

The burst of the technological bubble in the early 2000s propelled interest rates to historically low levels, setting the pace to housing price booms in a large number of developed countries. As the subprime mortgage market collapsed in the Summer of 2007, prices sharply fell, a long and persistent slump in the housing market began and the world economy witnessed the Great Recession.

These developments prompted a great deal of attention about the relevance of the housing market in explaining business cycle fluctuations (Mallick and Mohsin; 2016; Dufrénot and Malik 2012) and its close links with the financial sector (Granville and Mallick 2009; Sousa 2010a, b).

Most importantly, the severity and persistence of the Great Recession - and its roots on the sub-prime mortgage segment of the housing sector lending - highlighted four major aspects: 1) the importance of assessing the intricate effects of securitization and mortgage market development and transformation on the duration of housing booms and busts; ${ }^{1}$ 2) the relevance of integrating the impact of housing finance characteristics and institutional mortgage market differences on the likelihood of housing booms (busts) ending in a way that is informative for the design of a preventive macro-prudential toolkit; 3 ) the pertinence of a thorough calibration of government participation in housing finance to avoid the potential exacerbation of housing price swings; and 4) the general need to better understand the characteristics of the different phases of the housing cycle and the specific factors underpinning them (Loungani 2010a, b; Igan et al. 2011, 2012). These are the key goals of our paper.

Using quarterly data for a group of 20 OECD countries and relying on continuoustime and discrete-time Weibull models, we show that being part of the group of countries where the degree of securitization of the housing market is high does not significantly affect the length of housing booms. However, there is evidence, albeit weak, that reveals that a move towards a more liberalized mortgage sector is associated with longer housing booms: a one unit rise in the degree of mortgage sector liberalization reduces the likelihood of the end of a housing boom by, approximately, $68.5 \%$. In contrast, when the degree of securitization or the degree of development of the mortgage sector is high, housing busts tend to be shorter, with the hazard rate of a housing bust ending rising by a scale factor of close to 1.5 .

\footnotetext{
${ }^{1}$ In recent years, technological innovations in the mortgage industry and the increasing role played by technology-based ("FinTech") lenders led to faster processing of mortgage applications, an alleviation of capacity constraints associated with traditional mortgage lenders and an expansion of credit supply (Fuster et al. 2018).
} 
We also find that the length of housing booms and busts is particularly sensitive to some housing finance characteristics. For instance, mortgage equity withdrawals tend to make housing booms longer and to reduce the duration of housing busts. Thus, when households can borrow against accumulated housing equity, credit can be boosted in the context of a rise in house prices. By keeping debt service-to-income ratios affordable, high average typical terms (in years) can also help to prolong the duration of housing booms. There is also some evidence showing that longer housing booms and shorter housing busts emerge when: $(i)$ the issuance of covered bonds increases; ( $i$ i ) the typical loan-to-value ratio is high; ( $i$ ii $)$ households have the possibility of refinancing; and ( $i v$ ) there is some flexibility in the adjustment of the interest rate. Thus, high loan-to-value ratios propel borrowers to take out more debt and the absence of early repayment fees ease the ability of households to refinance their mortgage debt when interest rates fall. Greater development of the secondary market for mortgage loans goes in tandem with easier tap funding for lenders in the capital markets.

All in all, the economic significance of specific housing finance characteristics is of first-order magnitude: 1) a higher average typical term or a higher loan-tovalue ratio reduces the likelihood of the end of a housing boom by $5.7 \%$ or $2.5 \%$, respectively; 2) mortgage equity withdrawals allow a two- to three-fold increase in the odds of a housing bust ending; 3) a one percentage point increase in the issuance of covered bonds (as percentage of residential loans outstanding) raise the hazard rate of a housing bust ending by nearly $2 \%$; and 4 ) a one percentage point in the mortgage debt to GDP ratio raises the likelihood of a normal time spell ending by close to $1 \%$.

Finally, in what concerns government involvement in housing finance, our results show that some support measures can influence the length of housing market cycle phases. In particular, while tax deductibility of mortgage interest is associated with longer housing booms, capital gains tax deductibility is linked with shorter episodes of fast house price appreciation. Additionally, the provision of guarantees or loans from state-owned or state-sponsored financial institutions and finance agencies can prolong the duration of housing booms. As for housing busts, the empirical evidence corroborates the idea that greater participation of the government in the mortgage market is not necessarily a shield against such phases of the housing market cycle. However, early withdrawals (for house purchase) from provident funds - as a way of providing liquidity to the mortgage sector - can be effective at reducing the duration of housing busts.

From a policy perspective, our work emphasizes that housing finance regulation can help mitigating undesirable "boom-bust" house price fluctuations. It also shows how monetary policy can crucially complement it (Granville and Mallick 2009; Mallick and Mohsin 2010, 2016; Sousa 2010b; Castro 2011; Arslan et al. 2015a). Finally, it reveals that government participation in housing finance should be carefully designed to avoid unintended consequences (such as, an amplification of house price fluctuations).

The rest of the paper is organized as follows. Section "Review of the Literature" reviews the existing literature on housing market. Section "Modelling Approaches" presents the econometric model, while "Data" describes the data. Section "Empirical Analysis" discusses the empirical results. Finally, Section "Conclusions" concludes. 


\section{Review of the Literature}

A number of regional, country-level and cross-country studies has explored the relationship between the housing sector dynamics and fluctuations in various indicators of real economic activity (Leung 2004; Tsatsaronis and Zhu 2004; Ceron and Suarez 2006; Dufrénot and Malik 2012; Poghosyan 2016). For instance, Hiebert and Roma (2010) find that, despite the synchronized cycles in national aggregates, income differentials largely explain the dispersion of house prices across cities, and Gattini and Hiebert (2010) highlight the importance of the housing demand and the financing cost as driving housing prices. $^{2}$

Other studies have investigated the linkages between the housing cycle and the financial cycle (Englund and Ioannides 1997, Loungani 2010a, b, Igan et al., 2011, 2012; Anundsen et al. 2016). For example, changes in the availability of credit typically translate into fluctuations in the so-called "shadow cost of capital" or in risktaking behaviour (Rajan 2005). Similarly, monetary policy actions influence housing market returns (Chang et al. 2011) and temporary reductions in the risk-free interest rate can have a moderate to strong impact on house prices (Arslan 2014, 2015a). Sá and Wieladek (2015) also argue that declining interest rates and capital inflows tend to be associated with house price appreciation. Thus, monetary policy actions can have amplified effects on housing prices. Sá (2016) finds that foreign investment emanating from positive economic shocks abroad has a positive impact on house price growth. Leung and $\mathrm{Ng}$ (2018) show that, since the global financial crisis, the business cycle frequency links between the housing market and macroeconomic variables have weakened, while the relationship between the housing sector and financial variables has strengthened.

An important body of research (that has typically relied on a dynamic stochastic general equilibrium (DSGE) approach) evaluates the impact of macro-prudential policies on the housing sector. For instance, Kannan et al. (2012) find that a strong monetary response to emerging financial vulnerability that translates into rising credit growth and housing prices plays an important macroeconomic stabilization role. In the presence of financial sector or housing demand shocks, macro-prudential policies specifically tailored to counteract the credit cycle would also be stabilizing. However, house price booms caused by productivity shocks should not be dampened by macro-prudential authorities. Arslan et al. (2015a) show that macro-prudential policies (such as, higher thresholds for the minimum downpayment requirement) lead to a substantial stabilization of house prices. Rubio and Carrasco-Gallego (2017) perform an analysis using a two-country (i.e. Spain and the rest of the European Monetary Union (EMU)), two-sector DSGE model with housing that reveals that: (i) loose credit conditions associated with a rise in housing demand propel housing booms; and (ii) macro-prudential policies (in the form of countercyclical loan-to-value (LTV) rules reacting to deviations of house prices and output from their steady states) could

\footnotetext{
${ }^{2}$ Interestingly, Arslan et al. (2015b) decompose housing price changes into a anticipated and unanticipated variation, and find that the former has a positive impact on transaction volume while the latter has a negative effect. A positive link between house prices and transaction volume is also uncovered by Leung et al. (2002) and Ortalo-Magne and Rady (2006).
} 
have avoided financial crises triggered by excessive credit growth. Kelly et al. (2017) analyze the relationship between credit and house prices and macro-prudential policy through a micro-empirical lens. The authors use loan-level data to build a measure of credit availability that varies as a function of borrower's age, income, interest rates and wealth, and market conditions concerning debt service ratios (DSR), loan-toincome ratios (LTI) and loan-to-value ratios (LTV). They find that a $10 \%$ rise in credit availability is associated with a $1.5 \%$ increase in house prices. Moreover, macroprudential policies, the level of the limits at which they are set and the timing of their introduction, can have a large impact on house prices.

Another strand of literature assesses how the so-called "underwriting technology" has improved the mortgage market and impacted the global financial crisis of 2008-2009. For instance, Green and Wachter (2005) and Cho (2007) put forward an extensive description of the historical evolution of the mortgage sector where the technological revolution started in the early nineties. Green and Wachter (2005) point to the important changes in the structure of the U.S. mortgage market over time, namely, in terms of down payment size, interest rates flexibility and maturity. These developments in mortgage finance and innovations in financial engineering and portfolio optimization facilitated the expansion of mortgage markets and eased households' access to finance. Compared to other countries, the U.S. mortgage sector also provides more options, at more attractive terms, to borrowers and with large benefits for homeowners and the economy as a whole. In the same line, Cho (2007) notes that a well-functioning mortgage intermediation system is based on: $(i)$ affordability enhancement; ( $i$ i ) intermediation efficiency; and (iii) risk management. The author also stresses that "right sequencing" can allow the evolution of such system towards a market-based one in a way that maximizes consumers' welfare. Additionally, Fuster et al. (2018) highlight that technology-based ('FinTech") lenders have enhanced the efficiency of financial intermediation at no cost of higher defaults. By contrast, Anderson et al. (2011) and Capozza and Van Order (2011) argue that the surge in defaults at the onset of the global financial crisis was the outcome of the deterioration in both economic conditions and underwriting quality, albeit the empirical evidence is not consensual about whether moral hazard in "non-agency" securitization led to underwriting risk mispricing or not. Specifically, favourable housing market conditions tend to mask worsened underwriting quality, thereby, stimulating mortgage lending. Therefore, when there is a reversal of such conditions mortgage defaults surge and foreclosure rates rise. In this context, the probability of a housing boom turning into a bust increases.

Some authors have focused on the drivers behind asset market boom-bust cycles. Bordo and Jeanne (2004) show that asset price busts are generally associated with a slowdown in economic activity and a rise in financial stress. Bordo and Landon-Lane $(2013,2014)$ argue that expansionary monetary policy can create booms in equity, housing and commodity markets. Loungani (2010a, b) points out that, although economic theory links the pattern of house prices with the behaviour of rents and income in the long run, behavioural factors, interactions with financial markets, misperceptions about fundamentals, (monetary) policy changes and supply constraints may have an impact on the short-term dynamics. Agnello and Schuknecht (2011) rely on a multinomial probit model to estimate the probability of occurrence of housing booms 
and busts. They find that an ease in credit conditions is prone at leading to housing booms, while banking crises are likely to generate housing busts. Igan et al. (2011) assess the comovement of credit, house prices, interest rates and real economic activity. Interestingly, the empirical evidence suggests that house price cycles tend to lead business and credit cycles over the long-term and interest rate cycles lag them. In the same vein, Igan and Loungani (2012) examine the dynamics of house prices and stress that it can be driven by demographic factors and income, but changes in credit conditions and fundamentals are likely to generate deviations from the implied equilibrium levels. Sá et al. (2014) use a panel VAR model to study the effect of shocks to capital inflows on the housing market in OECD countries and show that they have a positive effect on real house prices, thus, leading to the occurrence of housing booms.

Finally, it should be noted that the majority of theoretical and empirical studies in the field have looked at either the dynamics of real house prices per se or the timing of periods of negative or positive house price growth. Yet, analogously to the case of economic recessions (where predicting the timing of their occurrence is relevant), or the case of unemployment (where knowing its magnitude at a given moment in time provides a grasp of labour market conditions), it is, nevertheless, the length of these phenomena that concerns policymakers the most because of their associated welfare implications (Kiefer 1988). In this context, the housing market cycle has been analyzed through the lens of duration analysis. For instance, Cunningham and Kolet (2011) estimate a discrete-time survival model and find positive duration dependence in housing market expansions, but not in contractions. Bracke (2013) relies on a similar econometric framework to show that pronounced house price upturns tend to be followed by abnormally long house price downturns.

Agnello et al. (2015) extend the baseline continuous-time Weibull model to the duration of periods of booms, busts and normal times in the housing markets and explore a second dimension of housing price cycles: the existence of breaks or change-points in the duration dependence parameter. The authors show that positive duration dependence is present in booms and busts that last less than 26 quarters, but that does not seem to be the case for longer phases of the housing market cycle. Agnello et al. (2017) look at spillovers from the oil sector to the housing market cycle. The authors find that the length of housing booms is reduced when oil prices increase. Moreover, net oil-importing countries tend to be more vulnerable to protracted housing slumps than net-oil exporters. Focusing on a discrete-time Weibull model, Agnello et al. (2018a) uncover a strong dependence of the various phases of the housing market cycle on real GDP growth, with credit market conditions being especially relevant at shaping the length of housing booms. Agnello et al. (2018b) quantify a two- to threefold increase in the likelihood of the end of a housing boom due to financial crisis recessions and an almost twice as large probability of an increase in the duration of housing market busts due to such type of recession episodes. ${ }^{3}$

\footnotetext{
${ }^{3}$ For an application of duration analysis to the study of the determinants of the length of fiscal consolidation programs, see Agnello et al. (2013). Agnello et al. (2018c) also rely on it to study the "legacy" and the "tyranny" of time on the exit and the re-entry of sovereigns to international capital markets. Finally, Agnello et al. (2018d) assess the duration of financial markets' shutdown and re-access.
} 
Our contribution to the above mentioned literature is threefold. First, we assess the effect of securitization and mortgage market development on the duration of housing booms, busts and normal times. Second, we quantify the impact of housing finance characteristics and institutional mortgage market differences on the length of the different phases of the housing market cycle. Third, we investigate the impact of government participation in housing finance on the length of the housing booms and busts. These issues are particularly important, as they help understanding the role that macroprudential policy can play as a line of defense vis-à-vis housing boom-bust cycles (Kannan et al. 2012; Arslan et al. 2015a; Rubio and Carrasco-Gallego 2017; Kelly et al. 2017). They also shed light on the optimal mix of policies - that is, the potential complementarity between monetary policy and housing finance regulation - as a way of effectively handling housing market imbalances that create financial stability risks (Rubio and Carrasco-Gallego 2014; Bailliu et al. 2015; Falagiarda and Saia 2017; Gelain and Ilbas 2017; Arslan and Upper 2017). ${ }^{4}$ Finally, they contribute to a clear-cut evaluation of the potentially unintended consequences of greater government involvement in the mortgage market, as well as the proper design of support measures that can mitigate them.

All in all, our work is inspired by the studies of Leung (2007, 2014), Iacoviello (2005) and Chen and Leung (2008) and Chen et al. (2014) and sheds more light on our understanding of the housing price dynamics. Specifically, in a creditless world, house prices either follows an auto-regressive process (Leung 2007) or can be described as an error-correction model (Leung 2014). By contrast, in a world with permanent binding credit and collateral constraints, the house price dynamics can be characterised by a Vector Auto-Regressive (VAR) framework (Iacoviello 2005). And, when collateral constraints bind only infrequently, house prices are well approximated by a regime-switching model (Chen and Leung 2008, 2014). ${ }^{5}$ Our paper corroborates this last empirical evidence and characterisation of the data, as our results confirm that certain macro-financial variables do not exert the same effect

\footnotetext{
${ }^{4}$ Several authors use DSGE models to assess the interaction between monetary and macro-prudential policies. For instance, Bailliu et al. (2015) look at such linkages and find that the welfare benefits of responding to financial imbalances are larger in the presence of financial shocks with a broad macroeconomic impact. In this context, the coordination of monetary and macro-prudential policies is crucial. Along the same line, Falagiarda and Saia (2017) show that the presence of endogenous loan-to-value (LTV) ratios amplifies lending pro-cyclicality. Interestingly, the authors find that in normal times, macro-prudential policies can lead to excessive credit and macroeconomic volatility. By contrast, in periods of financial stress, such prudential regulatory frameworks can significantly improve financial and macroeconomic stability. Gelain and Ilbas (2017) argue that potential gains from coordination between a flexible inflation targeting central bank and a macro-prudential regulator charged with the financial stability mandate are a function of the importance given to the output gap in the macro-prudential policy reaction function. In a similar fashion, Rubio and Carrasco-Gallego (2014) show that when monetary and macroprudential policies are coordinated, there is a financial stability improvement and a welfare gain for the society as a whole, albeit borrowers should compensate savers' welfare losses in order to achieve superior economic outcomes. Using questionnaire responses, Arslan and Upper (2017) uncover evidence suggesting that macro-prudential policies are frequently designed for specific sectors (in particular, the real estate sector) or institutions (reducing credit procyclicality and mitigating baking sector risk). Moreover, the effectiveness of such policies tends to be maximized when they are accompanied by countercyclical monetary policy.

${ }^{5}$ For instance, Chen et al. (2014) estimate a regime-switching model of house prices, and show that inflation and interest rate are the most robust determinants.
} 
across the various phases of the house price cycle. Instead, they are more prone at influencing the duration of certain phases than others (Agnello et al. 2018a).

Our empirical findings are also indebted to the research by Almeida et al. (2005), Peek and Wilcox (2006) and Chiquier and Lea (2009) among others, who analyze the sensitivity of house price fluctuations to housing finance policy in general and the development, growth and (government) institutional framework of the secondary mortgage market in particular. We focus on the duration of housing market cycle phases instead of looking at the magnitude of house price changes or volatility, as the former is especially relevant from a (welfare) policy perspective. And the empirical evidence of our paper gives support to a significant role played by housing finance and its inter-linkages with the house price dynamics.

\section{Modelling Approaches}

\section{The continuous-time duration model}

Our modelling approach is based on duration analysis, which we employ to investigate the importance of securitization and the degree of development/liberalization of the mortgage sector on the length of housing booms, busts and normal times. The three duration variables required for this analysis are defined in spells of time, that is, the number of quarters over which either a boom, bust or normal time in housing prices takes place. After measuring these events, we follow Agnello et al. (2013, 2015, 2017, 2018a, b, c) and rely on a Weibull distribution to obtain the hazard function

$$
h(t, \mathbf{x})=\alpha p t^{p-1} \exp \left(\beta^{\prime} \mathbf{x}\right),
$$

where $\alpha p t^{p-1}$ represents the baseline hazard function that captures the duration dependence in the data, $\alpha$ is a positive constant, $p$ is also positive and parameterizes the duration dependence, $\beta$ is a $(K \times 1)$ vector of parameters to be estimated and $x$ is a vector of time-invariant covariates. ${ }^{6}$ If $p>1(p<1)$ there is positive (negative) duration dependence; if $p=1$, there is no duration dependence.

Thus, the survival function can be expressed as

$$
S(t, \mathbf{x})=\exp [-H(t, \mathbf{x})]=\exp \left[-\alpha t^{p} \exp \left(\beta^{\prime} \mathbf{x}\right)\right] .
$$

where $H(t)=\int_{0}^{t} h(u) d u$ represents the integrated hazard function.

\footnotetext{
${ }^{6}$ The model can be estimated without imposing any specific functional form on the baseline hazard function (as in the so-called Cox model) or, in the absence of duration dependence, via the characterization of the baseline hazard function by means of the exponential distribution. However, in the presence of duration dependence - which is confirmed by our regressions - alternative models (such as, the Weibull model that we use) that impose a specific parametric form are preferable. Other alternative parametric distributions include: (i) the Gompertz distribution that allows for monotonically increasing (or decreasing) hazard functions only (i.e. similar to the case of the Weibull distribution); and (ii) the log-logistic, the log-normal, and the generalized Gamma (that includes the Weibull as a particular case) distributions that also allow for non-monotonic hazards (Jenkins 2005).
} 
This model is estimated by Maximum Likelihood and the log-likelihood function for a sample of $i=1, \ldots, n$ spells is written as ${ }^{7}$

$\ln L(\cdot)=\sum_{i=1}^{n}\left[c_{i} \ln h\left(t_{i}, \mathbf{x}_{i}\right)+\ln S\left(t_{i}, \mathbf{x}_{i}\right)\right]=\sum_{i=1}^{n}\left[c_{i}\left(\ln \alpha+\ln p+(p-1) \ln t_{i}+\beta^{\prime} \mathbf{x}_{i}\right)-\alpha t_{i}^{p} \exp \left(\beta^{\prime} \mathbf{x}_{i}\right)\right]$,

where $c_{i}$ indicates when the observations are censored, that is: they are censored $\left(c_{i}=0\right)$ if the sample period ends before the turning point is observed; and they are not censored $\left(c_{i}=1\right)$ if the turning point is observed before the end of the sample period.

This continuous-time setup may not be the most appropriate for this type of analysis. First, housing prices are observed in discrete time. Second, most of the regressors that we use vary over time. This means that we also need to consider a discrete-time duration model.

\section{The discrete-time duration model}

According to Allison (1982), when the discrete units are very small, time can be treated as if it is continuous. However, when those time units are very large, a discrete-time duration analysis can be more effective. This issue is relevant in the case of housing market cycles, where the available data is grouped into large (quarterly) discrete-time intervals. Moreover, by using a discrete-time duration model, we can account more easily for important time-varying covariates in its specification.

Prentice and Gloeckler (1978), Allison (1982), Kiefer (1988), and Jenkins (1995) develop a discrete-time duration model, and derive the appropriate estimator for data grouped into intervals. To set the model, we observe $n$ independent spells $(i=1,2, \ldots, n)$ at each discrete point in time $(t=1,2,3, \ldots)$. The observation continues until time $t_{i}$, at which either an event occurs or the observation is censored (i.e. the event is observed at $t_{i}$, but not at $t_{i+1}$ ). Hence, the discrete-time hazard rate can be written as $P_{i t}=\operatorname{Pr}\left[T_{i}=t \mid T_{i}>t, x_{i t}\right]$, where $T_{i}$ is a non-negative discrete random variable denoting the uncensored time of occurrence of the event, and $x_{i t}$ is a vector of time-varying explanatory variables.

Assuming that the data are generated by a discrete-time analogue to the Weibull model presented above, the hazard function can be written as:

$$
P_{i t}=1-\exp \left[-h_{t} \exp \left(\beta^{\prime} \mathbf{x}_{i t}\right)\right]=1-\exp \left[-\exp \left(\theta+(p-1) \ln t+\beta^{\prime} \mathbf{x}_{i t}\right)\right],
$$

where $\theta+(p-1) \ln t$ is the logarithm of the baseline hazard function, $\theta$ is a positive constant, $p$ is the duration dependence parameter, $t$ denotes time, $\beta$ is a $(K \times 1)$ vector of parameters to be estimated and $x_{i t}$ is a vector of time-varying covariates. ${ }^{8}$

We can express (4) as

$$
\ln \left[-\ln \left(1-P_{i t}\right)\right]=\theta+(p-1) \ln t+\beta^{\prime} \mathbf{x}_{i t},
$$

\footnotetext{
${ }^{7}$ See Allison (1982) and Kiefer (1988), for details.

${ }^{8}$ This implies that both continuous-time and discrete-time models provide estimates of the same parameter, as long as a proper interval for the observations is chosen. This is defined in a way that the actual values of the covariates are constant over the interval.
} 
which is the so-called the complementary log-log transformation.

Following Prentice and Gloeckler (1978) and Allison (1982), the discrete-time $\log$-likelihood function for a sample of $i=1, \ldots, n$ events is given by:

$$
\ln L(\cdot)=\sum_{i=1}^{n} \sum_{j=1}^{t_{i}} y_{i t} \ln \left(\frac{P_{i j}}{1-P_{i j}}\right)+\sum_{i=1}^{n} \sum_{j=1}^{t_{i}} \ln \left(1-P_{i j}\right),
$$

where the dummy variable $y_{i t}$ is equal to one if the specific event of interest $i$ ends at time $t$, and zero, otherwise. And plugging (4) into (6), ${ }^{9}$ this model can be estimated by Maximum Likelihood.

\section{Data}

Quarterly data on the housing prices index $(H P I)$ are provided by the Organisation for Economic Co-Operation and Development (OECD) and covers a sample of 20 OECD countries over the period 1970Q1-2015Q4. ${ }^{10}$

We identify the various stages of the housing market cycles using a novel approach applied by Agnello et al. (2015, 2017, 2018c) and Burnside et al. (2016). Avdjiev et al. (2017) also rely on this framework to establish the phases of the credit cycle, respectively. In this context, quarterly house price growth is smoothed using a centred moving average. Then, we detect periods of consecutive upturns (i.e. positive growth) and downturns (i.e. negative growth) in the smoothed series, thus, dating its turning points (i.e. peaks and troughs). ${ }^{11}$ Next, we build on historical variation to set (average) thresholds of (cumulative) house price growth. Finally, if cumulative growth over a period of consecutive upturns (downturns) exceeds (falls below) a minimum (maximum) bound, it is labelled as a boom (bust); all other (upturn and downturn) episodes denoting cumulatively small fluctuations in housing prices are identified as normal times. Thus, while normal times are typically periods where house prices are

\footnotetext{
${ }^{9}$ There are other functions that can be considered for the baseline hazard function like polynomial-in-time specifications, piecewise-dummies, or fully non-parametric specifications with one dummy for each value of $t$ for which an event is reported (Agnello et al. 2013; Castro and Martins 2013). Nevertheless, one problem with the use of dummy variables is that the estimated hazard function may vary in time without a clear pattern and, consequently, the results may not be easily interpretable. Beck at al. (1998) suggest the use of "natural cubic splines" to smooth out the respective hazard function and coefficients. Given its flexibility, this alternative specification with a vector of cubic spline variables (cubic polynomials of $t$ ) will also be evaluated in this study.

${ }^{10}$ The countries included in our sample are: Australia, Belgium, Canada, Denmark, Finland, France, Germany, Greece, Ireland, Italy, Japan, Korea, Netherlands, New Zealand, Norway, Spain, Sweden, Switzerland, the United Kingdom, and the United States.

${ }^{11}$ Turning point analysis based on peak-trough dating is also widely applied in the identification of cycle phases (Diebold and Rudebusch 1991; Castro 2010).
} 
aligned with fundamentals, large positive (negative) deviations from fundamentals characterise periods of boom (bust). ${ }^{12}$

This procedure is particularly effective at replicating various stylized facts about the housing market behaviour, such as: ${ }^{13}(i)$ it explains why booms (busts) are marked by increases (decreases) in the number of agents who buy homes only because of large expected capital gains; $(i i)$ it shows that the probability of selling a home is positively correlated with house prices; (iii) it uncovers a positive correlation between sales volume and house prices; ${ }^{14}$ and, most importantly; and (iv) it is consistent with the empirical evidence that shows that while some housing booms are followed by busts, others are not. In this way, we are able to identify the observable determinants that are useful for predicting whether a boom will turn into a bust or not. ${ }^{15}$

After the identification of the different phases of the housing market cycle, we measure their duration, that is, we compute the number of quarters that a housing boom, bust or normal time lasts (Dur). In this way, the housing data used in duration analysis consists of spells of time.

Finally, we link the duration of each phase of the housing market cycle with three groups of factors, namely: (1) securitization and mortgage market development; (2) institutional differences in national mortgage markets; and (3) government participation in housing finance markets. To keep the empirical framework parsimonious, we include one factor at a time in the regressions. Additionally, factors that have been documented by the previous literature as capturing the dynamics of the macro-financial environment are controlled for. Table 1 provides a summary of the descriptive statistics of all variables included in the analysis. These are discussed in detail over the next sub-Sections.

\section{Securitization}

We follow Sá et al. (2014) and use the IMF index of securitization of the housing market (I M Findex). This indicator takes a high value if typical loan-to-value ratios

\footnotetext{
${ }^{12}$ For this reason, it is straightforward to argue that, holding changes of house prices constant, shorter housing busts are more favorable than longer ones. In the same vein, (long) housing booms are often followed by (long) housing busts. As noted by Bordo and Landon-Lane (2013), these can be very damaging because they typically lead to banking crises and prolonged economic recessions. Therefore, shorter housing booms should also be preferable to longer ones. Indeed, Agnello et al. (2015) show that when housing booms (busts) have a "short" duration, each additional quarter of duration, on average, increases the likelihood of the end of such phases of the housing cycle by a factor that is twice as large (in percentage points) compared to housing booms (busts) that have a "long" duration. This provides support to preventive policy interventions during periods of housing booms and busts.

${ }^{13}$ Yet, as highlighted by Leung and Feng (2005), commercial property prices display a very different behaviour from residential property prices.

${ }^{14}$ For a model rationalising the comovement between housing prices and transaction volume, see Arslan (2014). In the same line, Ortalo-Magne and Rady (2006) show that an increase of house prices eases downpayment requirement constraints, thus, leading to a rise in transaction volume.

${ }^{15}$ For a more detailed description of the identification procedure and the various episodes of housing booms, busts and normal times, see Agnello et al. (2015).
} 
Table 1 Descriptive statistics

\begin{tabular}{|c|c|c|c|c|c|}
\hline Variable & Obs. & Mean & Std. Dev. & Min. & Max. \\
\hline Booms & 1389 & 16.457 & 13.308 & 1 & 68 \\
\hline Busts & 717 & 16.509 & 15.885 & 1 & 85 \\
\hline Normaltimes & 1098 & 17.499 & 18.640 & 1 & 107 \\
\hline$G D P$ & 2874 & 0.658 & 1.678 & -11.34 & 17.74 \\
\hline Credit & 3370 & 2.698 & 5.083 & -45.44 & 84.09 \\
\hline$I R$ & 3171 & 9.302 & 4.767 & 0.50 & 37.15 \\
\hline European & 3400 & 0.701 & 0.458 & 0 & 1 \\
\hline IMFindex & 2890 & 0.514 & 0.205 & 0.23 & 0.98 \\
\hline HighIM Findex & 2890 & 0.471 & 0.499 & 0 & 1 \\
\hline MBSindex & 3060 & 0.334 & 0.392 & 0 & 1 \\
\hline HighMBSindex & 3060 & 0.389 & 0.488 & 0 & 1 \\
\hline MortgDebtGDPrat & 3060 & 53.389 & 25.504 & 13 & 116 \\
\hline MortgEqWithd & 2890 & 0.529 & 0.499 & 0 & 1 \\
\hline MortgBackSecIssues & 2550 & 4.973 & 4.724 & 0.10 & 20.10 \\
\hline AvTypTerm & 2890 & 22.412 & 5.019 & 15 & 30 \\
\hline CovBondIssues & 1530 & 10.344 & 17.403 & 0.70 & 58.50 \\
\hline TypLoanValuerat & 2890 & 75.176 & 8.185 & 50 & 90 \\
\hline Refinancing & 2890 & 0.235 & 0.424 & 0 & 1 \\
\hline Int RateAdjust & 3060 & 0.556 & 0.497 & 0 & 1 \\
\hline Subsidies First & 2210 & 0.077 & 0.267 & 0 & 1 \\
\hline SubsidiesBuyers & 2210 & 0.308 & 0.462 & 0 & 1 \\
\hline SubsidiesLowInc & 2210 & 0.154 & 0.361 & 0 & 1 \\
\hline Provident Funds & 2210 & 0.077 & 0.267 & 0 & 1 \\
\hline Hous Fin Funds & 2210 & 0.308 & 0.462 & 0 & 1 \\
\hline TaxDeduct & 2210 & 0.692 & 0.462 & 0 & 1 \\
\hline CapGains & 2210 & 0.923 & 0.267 & 0 & 1 \\
\hline GovParticIndex & 2210 & 0.318 & 0.118 & 0.13 & 0.56 \\
\hline AltGovParticIndex & 2210 & 0.319 & 0.106 & 0.13 & 0.50 \\
\hline
\end{tabular}

are high, when there is the possibility of mortgage equity withdrawal, and when secondary mortgage markets exist. The IMF index is constructed as in IMF (2008). Then, we consider a dummy variable (HighI M Findex), which takes the value of one when the IMF index is high (i.e. above the median value), and zero otherwise. As in Sá et al. (2014): the countries in the high IMF index group include the United States, Denmark, the Netherlands, Australia, Sweden, Norway, the United Kingdom and Canada; and the low IMF index group includes of Finland, Spain, Ireland, Japan, Italy, Belgium, Germany, Switzerland and France. Due to the absence of information, Greece, Korea and New Zealand are coded as missing regarding the IMF index. 


\section{Mortgage market development}

We also assess the importance of the development of the mortgage market. Thus, we rely on the work of Sá et al. (2014) and use the mortgage-backed security (MBS) index (MBSindex). This is a qualitative de jure indicator of the degree of securitization in the mortgage sector: it equals one if countries have a fully liberalized MBS market, and zero if no securitization is allowed. The MBS index is based on the information about mortgage-backed securities from IMF (2008) and about the start of mortgage securitization from the OECD (Girouard and Blöndal 2001), the ECB (2003) and national sources. Before the introduction of securitization, the MBS index takes the value of zero, after which the index is assigned a positive value between zero and unity, depending on the degree of securitization. For Australia (since 1995), Canada (since 1987), the Netherlands (since 1996), Spain (since 1992), the United Kingdom (since 1987) and the US (since 1971), the MBS index takes the value of one, as these countries have a liquid secondary MBS market since the respective year in which securitization was allowed de jure. In line with the work of Sá et al. (2014), the MBS index also takes the value of one in the case of Ireland (since 1996). Countries that do not have a liquid secondary MBS market but nonetheless allow a limited degree of securitization (e.g. in the form of special forms of covered bonds), which include Finland (since 1989), France (since 1991), Germany (since 1971), Sweden (since 1971) and Switzerland (since 1971), are assigned a value of 0.33. Similarly, New Zealand (since 1995), Italy (since 1999) and Denmark are assigned the value of 0.3 (Sá et al. 2014). The MBS index takes the value of zero in the case of Belgium, Japan and Norway. Due to the absence of information about the MBS index, Greece and Korea are coded as missing.

Additionally, we create a dummy variable (HighMBSindex), which takes the value of one when the MBS index is high (i.e. above the mean value), and zero otherwise. The countries included in the high MBS index are: Australia, Canada, the Netherlands, Spain, the United Kingdom, the United States and Ireland. The low MBS index group includes: Finland, France, Germany, Sweden, Switzerland, New Zealand, Italy, Denmark, Belgium, Japan and Norway. Greece and Korea are coded as missing.

\section{Institutional Differences in National Mortgage Markets}

To investigate the impact of cross-country differences in institutional characteristics of national mortgage markets on the various phases of the housing market cycle, we consider several dimensions, such as: 1) the ratio of mortgage debt to GDP (MortgDebtGDPrat); 2) the possibility of mortgage equity withdrawal (i.e. whether house equity release products are available and/or permissible or not) (MortgEqWithd); 3) the mortgage-backed security issues (as percentage of residential loans outstanding) (MortgBackSecIssues); 4) the average typical term (in years) (AvTypTerm); 5) the covered bond issues (as percentage of residential loans outstanding) (CovBondIssues); 6) the typical loan-to-value ratio (in percentage) 
(TypLoanValuerat); 7) the possibility of refinancing (i.e. whether fee-free prepayment is available and/or permissible or not) (Refinancing); and 8) the degree of interest rate adjustment (Int RateAdjust), which takes into account the breakdown of new loans into $(i)$ those with fixed interest rates (for more than five years or until expiry), ( $i i)$ those with mixed interest rates (i.e. fixed interest rates between one and five years); and ( ii i) those with variable interest rates (which are renegotiable after one year or tied to market rates or adjustable at the discretion of the lender).

In what concerns the mortgage debt to GDP ratio, we rely on the data provided by Calza et al. (2013) and Sá et al. (2014). Because of the lack of availability, data for Greece and Korea are coded as missing.

As for the possibility of mortgage equity withdrawal, we use data from the IMF (2008), Calza et al. (2013) and Sá et al. (2014). Again, data for Greece and Korea are treated as missing.

Data for the mortgage-backed security issues (as percentage of residential loans outstanding) is taken from the IMF (2008). Finland, Norway, New Zealand, Switzerland and Korea are coded as missing.

The number of years of the average typical term is gathered from the IMF (2008). New Zealand, Switzerland and Norway are coded as missing.

The data for covered bond issues is obtained from the IMF (2008). The countries with missing data are: Australia, Belgium, Canada, Greece, Italy, Japan, Norway, the United States, New Zealand, Switzerland and Korea.

The typical loan-to-value ratio is based on the data from the IMF (2008). New Zealand, Switzerland and Korea are coded as missing.

The information about the possibility of refinancing comes from the IMF (2008). In this case, fee-free prepayment is considered to be available and/or permissible in Denmark, the Netherlands, Sweden and the United States, and not available or nonpermissible in Belgium, Canada, Finland, France, Germany, Greece, Ireland, Italy, Japan, Norway and Spain. Countries where refinancing is limited (like Australia and the United Kingdom) are also included in the second group. For countries where data are not available (New Zealand, Switzerland and Korea), this indicator is treated as missing.

Finally, the degree of interest rate adjustment is sourced from Calza et al. (2013). In this context, interest rates are assumed to be mainly variable in Australia, Finland, Ireland, Italy, Japan, Norway, Spain, Switzerland and the United Kingdom, and fixed in Belgium, Canada, Denmark, France, Germany, the Netherlands, New Zealand, Sweden and the United States. Greece and Korea are coded as missing.

\section{Government Participation in Housing Finance}

Government participation in housing finance generally contributes to the purchase of affordable housing and, thus, expands homeownership. However, the presence of a dominant state-owned institution in domestic mortgage markets can also reduce the spectrum of available mortgage instruments, affect saving incentives for potential home buyers and limit financial sector competition. Thus, the overall impact of government support on the length of the various phases of the housing market cycle is unknown ex-ante, should depend on the specific form of support at place and calls for a proper assessment. 
The involvement of the government in the domestic mortgage sector can take different forms, ranging from social housing policies to benefit first-time and low-income home buyers, state-owned or state-sponsored financial institutions and finance agencies that originate mortgage loans or provide liquidity to the mortgage market, and tax incentives.

We consider different dimensions of government participation in housing finance, namely: ( $i$ ) up-front subsidies to first-time or other buyers (SubsidiesFirst); (ii) subsidies to buyers through savings account contributions or preferential fees (SubsidiesBuyers); (iii) subsidies to selected (low-income) groups (SubsidiesLowInc); (iv) early withdrawals for house purchase from provident funds (ProvidentFunds); $(v)$ housing finance funds or government agencies that provide guarantees/loans (HousFinFunds); (vi) tax deductibility of mortgage interest (TaxDeduct); and (vii) capital gains tax deductibility (CapGains). Following IMF (2011), all these forms of support can be equally aggregated in a composite index of government participation in housing finance (AltGov ParticIndex). When a state-owned institution is the largest market player, one can reflect this specific feature of housing finance by attaching a higher weight to this subcategory in the construction of the index (GovParticIndex).

In the case of social housing policies, subsidies to first-time or other buyers up-front are present in Australia. Subsidies to buyers through savings account contributions or preferential fees can be found in Australia, France, Germany and Spain. Subsidies to selected (low-income) groups are available in Australia and the US.

Concerning the presence of state-owned or state-sponsored financial institutions and finance agencies, we note that early withdrawals (for house purchase) from provident funds are possible in Canada, while housing finance funds or government agencies that provide guarantees or loans can be found in Canada, Japan, the Netherlands and the US.

In what concerns tax incentives, (tax) deductibility of both mortgage interest and capital gains is possible in Belgium, Denmark, France, Ireland, Italy, the Netherlands, Spain and the US. Deductibility of only mortgage interest is present in Japan, while for Australia, Canada, Germany and the UK only capital gains tax deductibility is available.

Finally, data for government participation in housing finance are missing for Finland, Greece, Korea, New Zealand, Norway, Sweden and Switzerland.

\section{Macro-financial environment}

The set of explanatory variables is completed with macro-financial indicators that the empirical literature has pointed out as key drivers of the housing price dynamics (Englund and Ioannides 1997; Agnello and Schuknecht 2011). These include: $(i)$ the growth rate of real GDP (GDP); (ii) the (lending) interest rate $(L R)$; and (iii) the growth rate of domestic credit to the private sector (Credit)

The lending rate corresponds to the bank rate that normally meets the shortand medium-term financing needs of the private sector, thus, being differentiated according to the creditworthiness of borrowers and the financing objectives. 
Domestic credit refers to the financial resources provided to the private sector by financial corporations (via loans, purchases of non-equity securities, and trade credits and other accounts receivable) that lead to a repayment claim. Financial corporations include deposit money banks and monetary authorities and other financial corporations (namely, finance and leasing companies, foreign exchange companies, insurance corporations, money lenders and pension funds) that do not accept transferable deposits but incur in liabilities, such as savings and time deposits.

All the variables capturing the macro-financial environment are expressed in real terms using the consumer price index (CPI) as the deflator, and they are gathered from the International Financial Statistics of the International Monetary Fund (IMF). ${ }^{16}$

Finally, along the lines of the work of Agnello et al. (2015), we consider a dummy variable (European) that accounts for geographical differences in the length of housing booms, busts and normal time spells. This dummy variable takes the value of one for European countries, and zero in the case of non-European countries. ${ }^{17}$

\section{Empirical Analysis}

\section{Securitization and mortgage market development}

Until the eighties, the mortgage market was highly regulated, which frequently led to interest rate ceilings, limits on the availability of mortgage credit and restrictions on repayment periods (Girouard and Blöndal 2001). However, over the past four

\footnotetext{
${ }^{16}$ We point to the fact that the economic variables are lagged one period in order to avoid simultaneity and to account for delays in data reporting. In this context, our models are not affected by potential endogeneity. More specifically: $(i)$ in our continuous-time duration model setup, each control variable is defined as the average over each specific spell (boom, bust or normal time). Thus, it is highly unlikely that length of a boom, bust or normal time spell drives the average of the control variables over each of those spells; (ii) in discrete-time duration frameworks, regressing a linear approximation of the nonlinear model using an Instrumental Variables (IV) estimator and time controls does not guarantee outperformance compared to the estimation of a nonlinear model where potential endogeneity is ignored; and (iii) the dependent variable of our duration model specifications is the probability of the end of the event, not the probability of occurrence of the event itself. This means that our models quantify, for instance, the impact of GDP growth on the likelihood of the end of each phase of the housing price cycle, not the likelihood of occurrence of each phase of the housing price cycle. Therefore, endogeneity in the form of reverse causality of a potential impact of the likelihood of the end of each phase of the housing price cycle on GDP growth or any other control variable does not hold at all in duration models like ours.

${ }^{17}$ We account for potential cross-country unobserved heterogeneity. For parsimony and models' convergence, we do not include country fixed-effects (captured by country dummy variables) in our regressions, but consider instead a single dummy variable (European). Indeed, due to the relatively small number of spells, one cannot perform sub-sample analysis. However, the sample correlations between MBSindex and HighMBSindex, and (i) IMFindex, (ii) all institutional characteristics of national mortgage markets, and (iii) all indicators of government participation in housing finance are generally quite small. These are available from the authors upon request. Consequently, in our sample, the degree of development of the mortgage market is not related with housing finance characteristics, the degree of securitization and the extension of government participation in housing finance. Thus, our models track the "direct" (i.e. pure) effect of financial market development economic systems, institutional settings or government involvement in housing finance on the duration of the different phases of the housing market cycle, not their "indirect" impact via unobserved differences in those dimensions.
} 
decades, the remarkable changes in the housing finance system of several industrialized countries have influenced the strength of the linkages between the housing sector and real economic activity. Indeed, the deregulation of mortgage markets pressed nontraditional lenders towards the adoption of competitive measures, thereby, extending lending services, increasing price responsiveness and broadening access to mortgage credit (Diamond and Lea 1992). Some authors suggest that, by easing the access to credit and, thus, allowing consumers to better smooth temporary fluctuations in disposable income, such relationship may have weakened (Dynan et al. 2006). Yet, it is also reasonable to assume that innovations in housing finance may have amplified the spillovers from the housing sector to the real side of the economy. In fact, the fast growth of mortgage debt cannot be detached from the wider availability and lower cost of housing financing. As Rajan (2005) argues, securitization leads to more risk-taking behaviour by banks and increases the sensitivity of banks to variations in the interest rates. Diamond and Rajan (2009) put forward the argument that securitization makes it possible for international investors to have a direct exposure in the mortgage market. Sá et al. (2014) also find that in countries where there is more securitization of the housing finance system, the responses of real house prices, private credit and residential investment to capital-inflow shocks tend be larger and more persistent than in countries that do not allow mortgage-backed securities.

Against this background, we focus on the role played by securitization and the degree of development of the mortgage market and analyze how they impact the duration of the different phases of the housing market cycle. A summary of the results can be found in Tables 2 (housing booms), 3 (housing busts) and 4 (normal times). Columns 1-4 present the results associated with the continuous-time (Weibull) duration model. Columns 5-8 report the findings for the discrete-time (Cloglog) model that is analogue to the continuous-time Weibull model. Columns 9-12 show the Cloglog regressions that are performed using natural cubic splines of the hazard functions.

The empirical evidence presented in Table 2 shows that the duration of housing booms is not significantly affected by the securitization of the housing finance system. In fact, neither the variable IMFindex, nor the dummy variable HighIMFindex is statistically significant. Thus, being part of the group of countries where the degree of securitization of the housing market is high is not associated with a longer housing boom episode. In what concerns the development of the mortgage market, we find evidence, albeit weakly, that a move towards a more liberalized mortgage market is linked with longer housing booms: the coefficient associated with the variable $M B$ Sindex in the continuous-time (Weibull) duration model is negative $(-1.156)$ and significant at the 5\% level. Thus, a one unit rise in this indicator reduces the likelihood of the end of a housing boom by, approximately, 68.5\%. Despite this, none of the coefficients associated with $M B$ Sindex in the other econometric frameworks, nor the dummy variable HighMBSindex are significant, which indicates that neither the development of the mortgage market per se, nor being in the group of countries with a high MBS index implies a significant difference in the length of housing booms.

As for housing busts, the empirical evidence reported in Table 3 is quite interesting. Indeed, it shows that both IMFindex and HighIMFindex variables are 


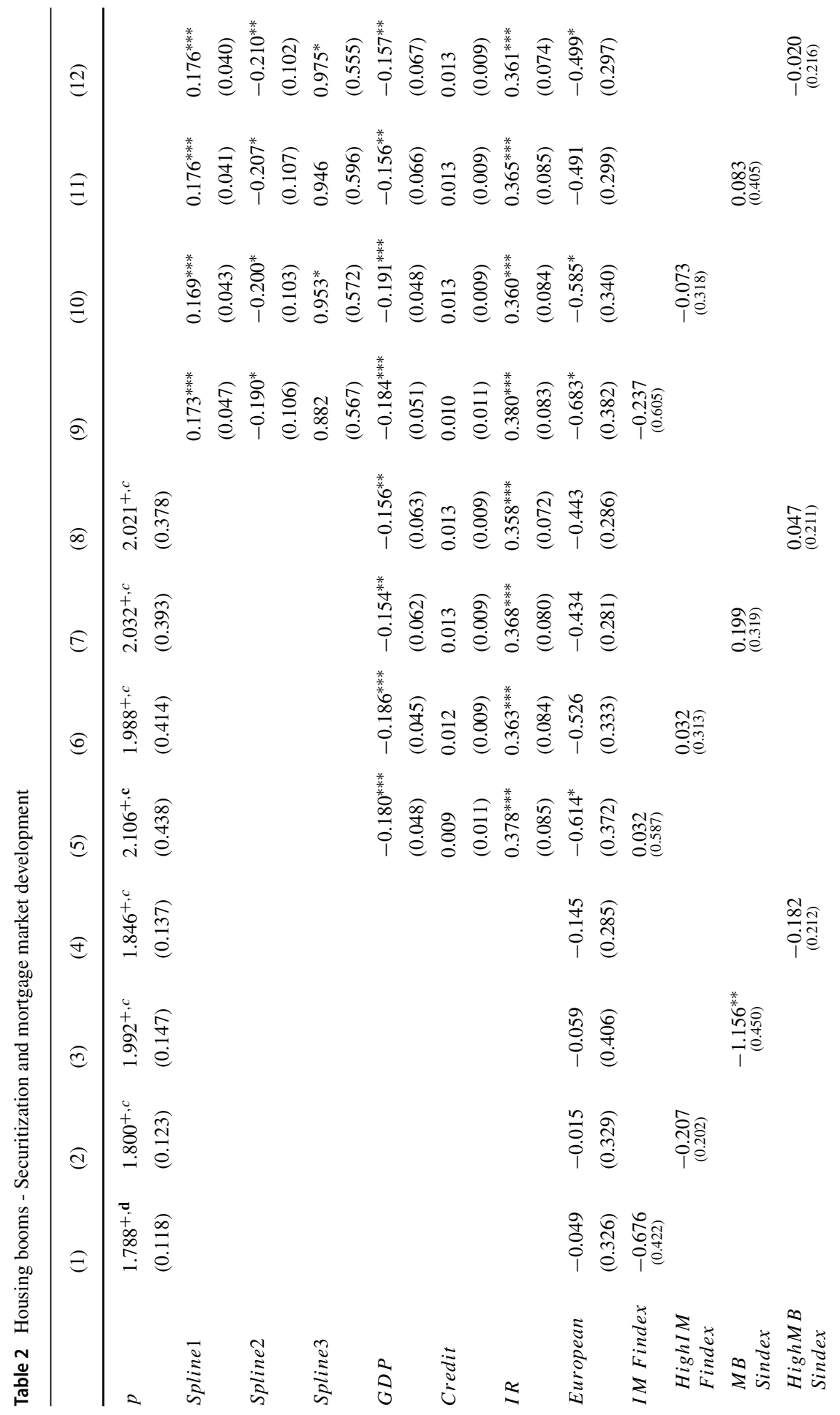




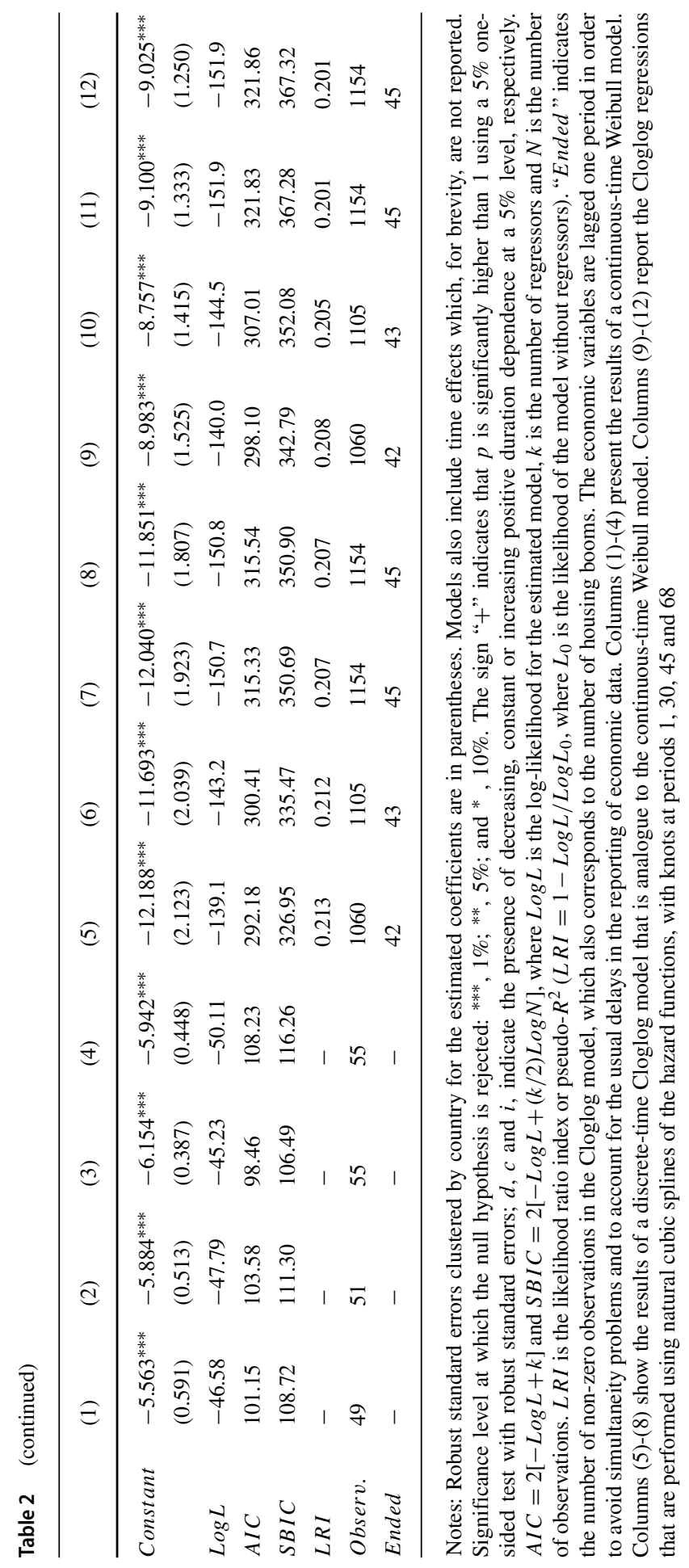




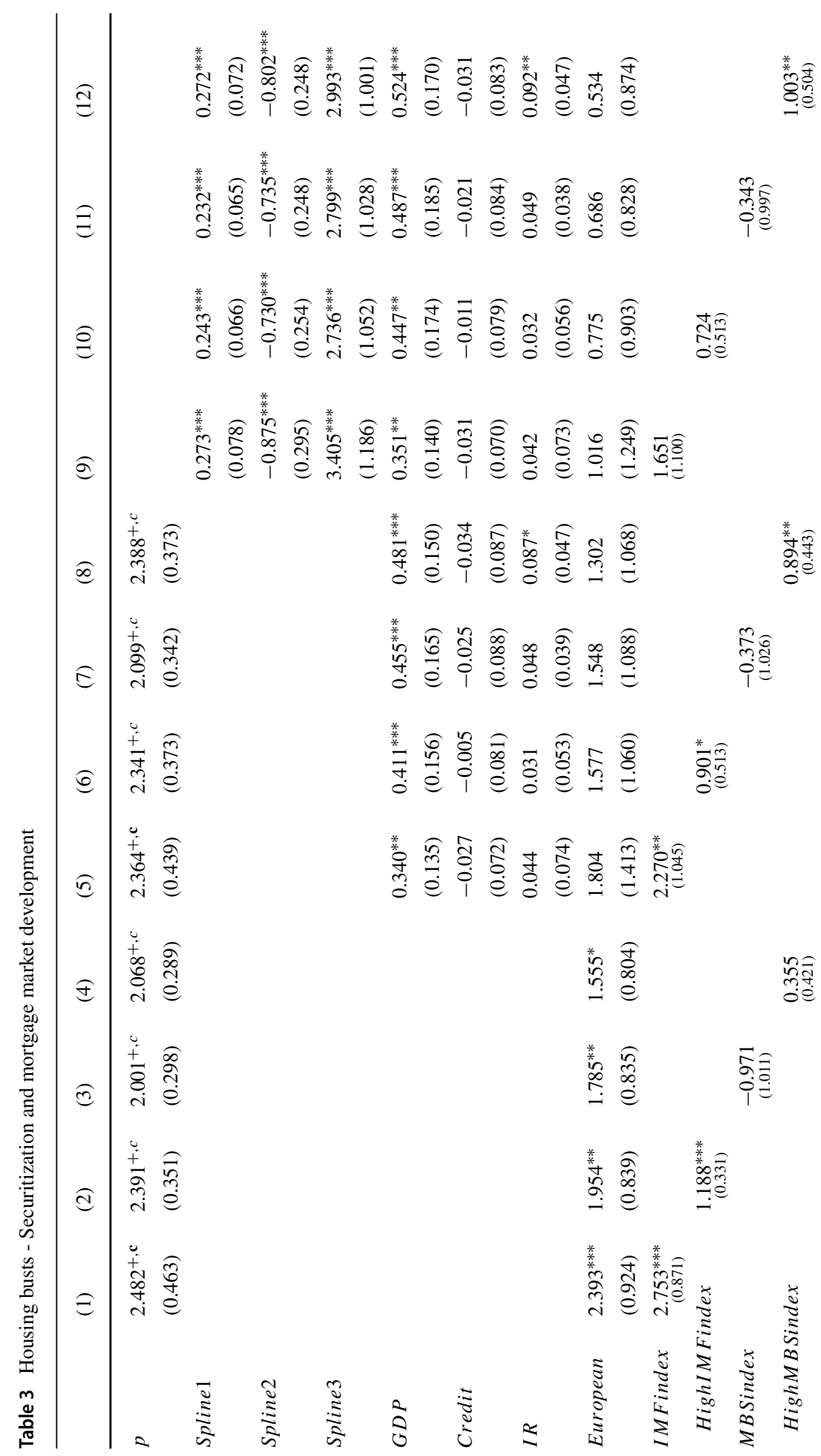




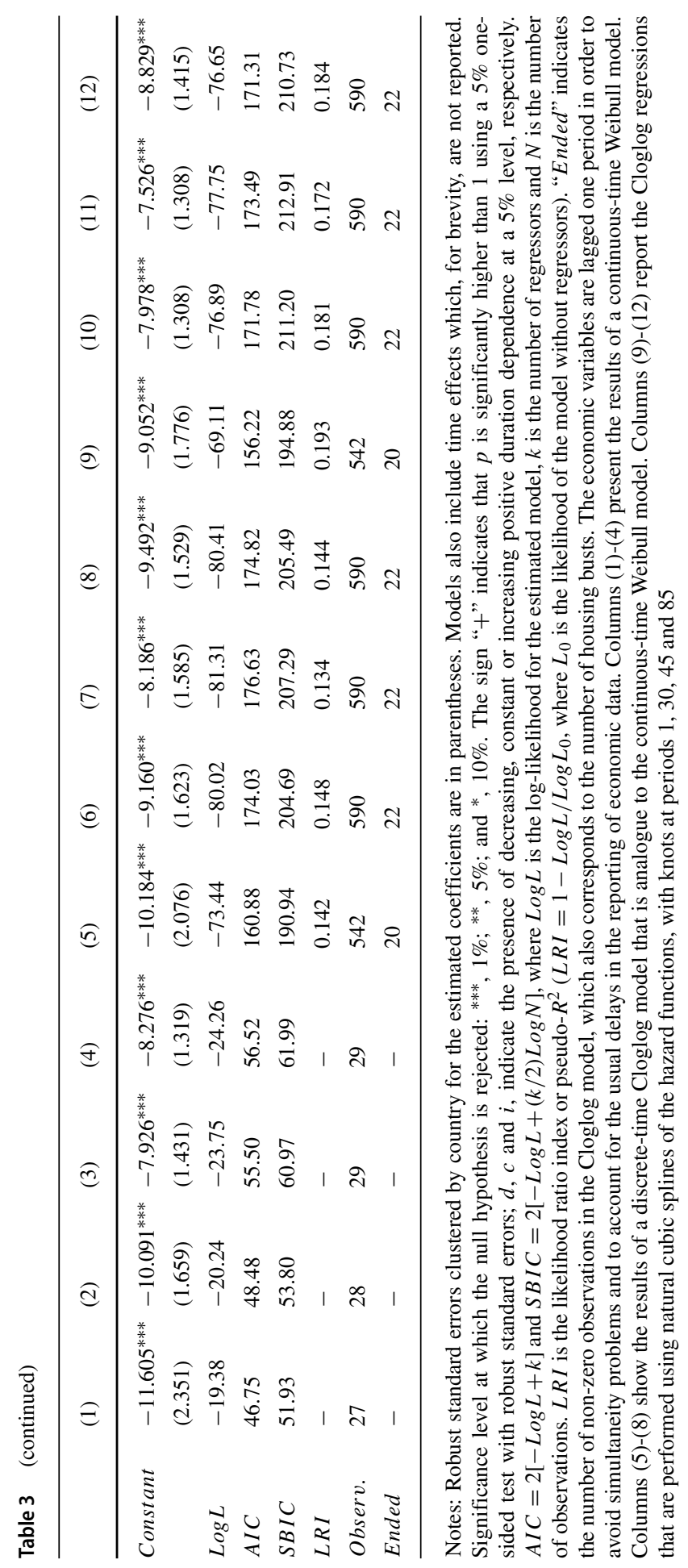




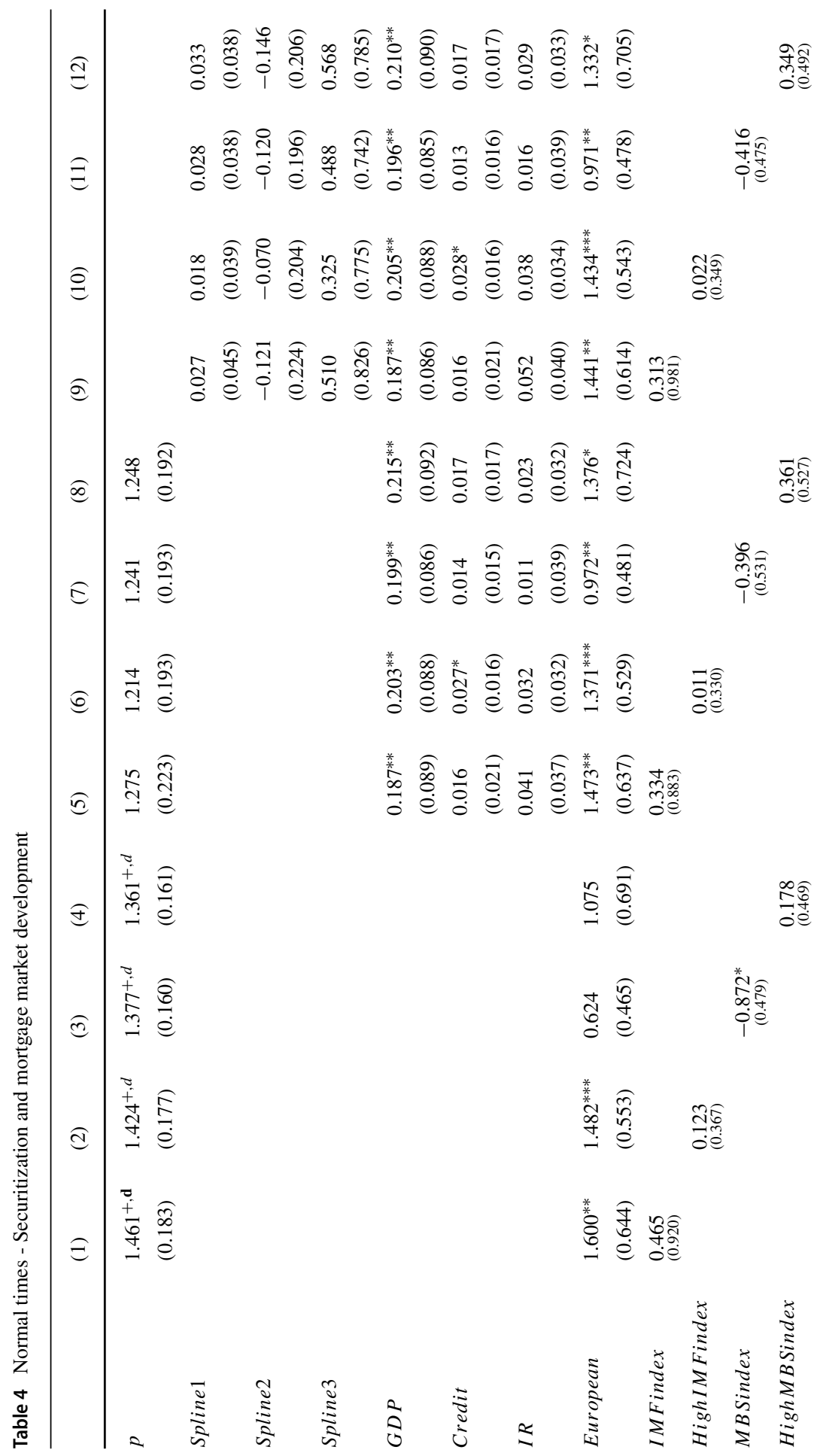




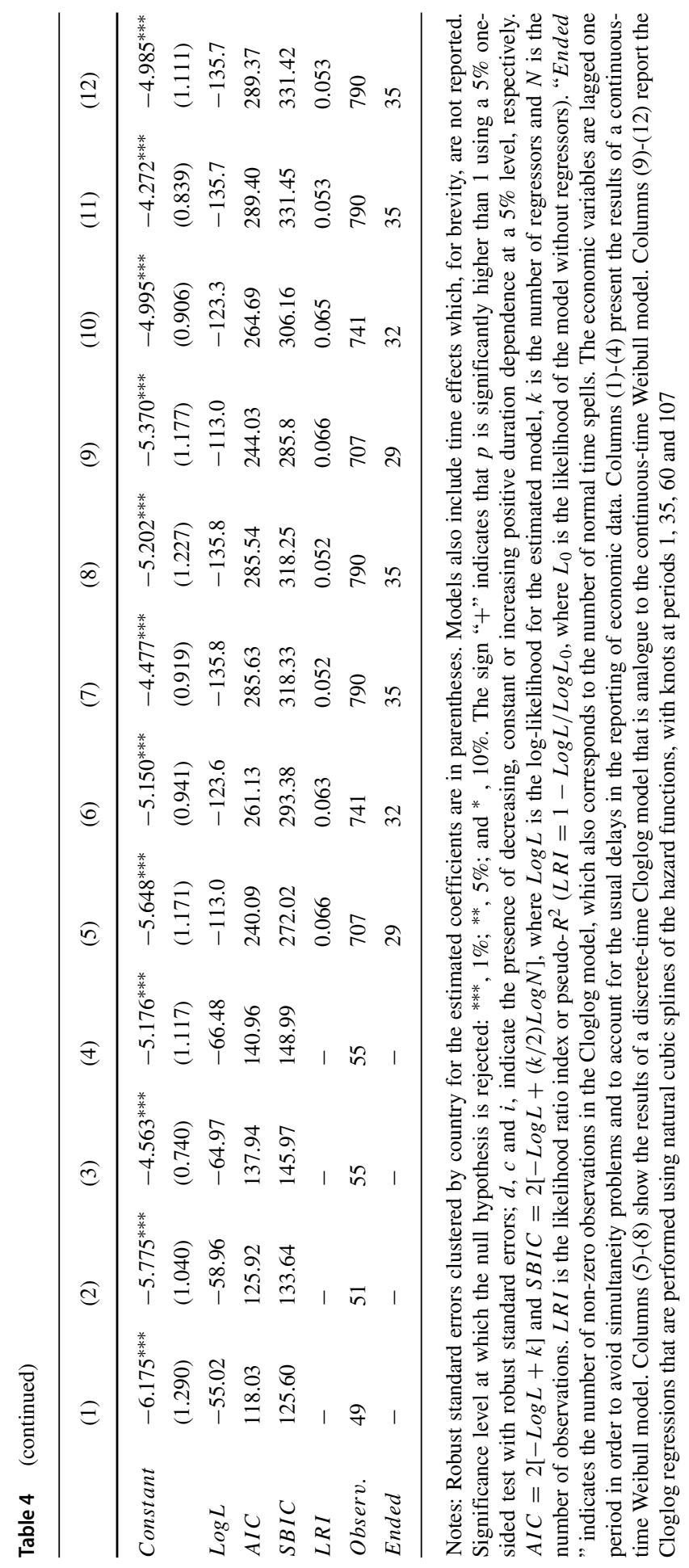


associated with shorter housing busts: the coefficients of these variables are positive and statistically significant (with the exception of the model with the natural cubic splines of the hazard function, even though the coefficients are also positive). Therefore, when the degree of securitization of the housing market increases or is high, the probability of the end of a housing bust rises, i.e. housing busts tend to be shorter. A similar result can be found vis-a-vis the role played by the development of the mortgage sector. In fact, although the variable $M B$ Sindex is not statistically significant across the three econometric frameworks under consideration, the dummy variable HighMBSindex displays a positive and significant coefficient (with the exception of the continuous-time (Weibull) model where no significance is uncovered). Consequently, being part of the group with a high degree of liberalization of the mortgage-backed security (MBS) sector implies an increase in the probability of the end of housing busts or, equivalently, reduces the duration of housing busts. This effect is quantitatively large: the hazard rate (or the odds) of a housing bust ending rises by a scale factor of between 1.4 and 1.7 when the country has a High MBS index.

Finally, with regard to normal times, the results shown in Table 4 do not give support to a significant effect of securitization or the development of the mortgagebacked security market on this phase of the housing market cycle. This is witnessed by the general lack of significance of the coefficients associated with IMFindex, HighIMFindex, MBSindex and HighMBSindex. In fact, among the four variables that we consider, the only occasion in which one of them is significant is when we estimate the continuous-time Weibull model with MBSindex. In this case, $M B$ Sindex has a negative coefficient $(-0.872)$ - which suggests that an increase in the degree of liberalization of the MBS sector makes normal times of the housing market somewhat longer -, but it is only significant at the $10 \%$ level.

\section{Institutional differences in national mortgage markets}

In the aftermath of the process of deregulation of mortgage markets that began in the eighties, the degree of competitiveness of the housing finance models in many industrialized countries increased dramatically. This has, in turn, translated into broader access to housing credit, new lending institutions and loan financial instruments and wider sources of funding

Despite this, there are still considerable cross-country institutional differences in national mortgage markets, reflecting various degrees of mortgage market liberalization and uneven dimensions in legal procedures and regulatory frameworks. Indeed, collateral constraints remain important determinants of the dynamics of the housing market and the existing literature emphasizes that, when the mortgage market allows for higher leverage ratios, the housing sector becomes more responsive to structural shocks (Iacoviello 2005; Ortalo-Magne and Rady 2006; Chen and Leung 2008; Calza et al. 2013). Bordo (2003) and Bordo and Jeanne (2004) highlight that preemptive monetary policy can be an insurance against the occurrence of low probability events, such as a national (rather than regional) house price busts, which have very detrimental macroeconomic effects. However, the authors emphasize that regulation and supervision can be more suitable for that purpose than traditional monetary 
policy instruments. Additionally, Rajan (2005) shows that securitization increases risk-taking practices by banks and boosts interest rate sensitivity, while Diamond and Rajan (2009) highlight the role of securitization in raising mortgage debt by packaging it into slices of different risk levels. Sá et al. (2014) argue that if securitization eases the occurrence of higher household leverage ratios, then, housing markets become more vulnerable to changes in the interest rate, a result that is consistent with the financial-accelerator mechanism. Put it differently, when the degree of development of the mortgage sector is high, household can get collateral services from a large fraction of the value of their houses. Thus, if household indebtedness is also high, small changes in the interest rate can have a major impact on their ability to service the debt.

Thus, this Section investigates the effect of cross-country differences in institutional characteristics of national mortgage markets on the various phases of the housing market cycle. The main findings are reported in Tables 5, 6 (housing booms), 7, 8 (housing busts) 9 and 10 (normal times). As in the previous exercises, we start by presenting the results of the estimation of the continuous-time (Weibull) duration model. Then, we report the findings associated with the discrete-time (Cloglog) model that is analogue to the continuous-time Weibull model. Finally, we show the Cloglog regressions that are performed using natural cubic splines of the hazard functions.

In the case of housing booms, the empirical results summarized in Tables 5 and 6 reveal that the mortgage debt (as percentage of GDP) (Mortg DebtGD Prat), as well as the issuance of mortgage-backed securities (MortgBackSecIssues), do not significantly influence the length of housing booms.

However, the possibility of mortgage equity withdrawals (Mortg EqWithd) tends to make housing booms longer. This finding is in line with the observation that by borrowing against accumulated housing equity, households can directly tap their net housing wealth, which fuels credit in the context of a rise in house prices. Therefore, housing booms last for longer time spans. Yet, the effect is weak, as it is only significant in the discrete-time model that is analogue to the Weibull model.

As for the average typical term (AvTypTerm), its coefficient is negative and significant - even though, only in the case of the Weibull model - thereby, implying that an increase in the average typical term reduces the likelihood of the end of a housing boom. In fact, by keeping debt service-to-income ratios affordable, longer repayment terms help to sustain episodes of housing booms.

The higher the issuance of covered bonds (as percentage of residential loans outstanding) (CovBondI ssues) is, the longer the housing booms will be. However, the impact of this indicator is only statistically significant in the discrete-time duration models. Additionally, we only find a weakly negative effect of the typical loan-tovalue ratio (TypLoanValuerat) on the duration of housing booms. This result is consistent with the idea that higher loan-to-value ratios propel borrowers to take out more debt and, thus, boost the occurrence of housing booms.

The possibility of refinancing (Refinancing) and more flexibility in the adjustment of the interest rate (Int Rate Adjust) also tend to lead to longer housing booms, even though the effect of these variables is only significant in the Weibull duration 


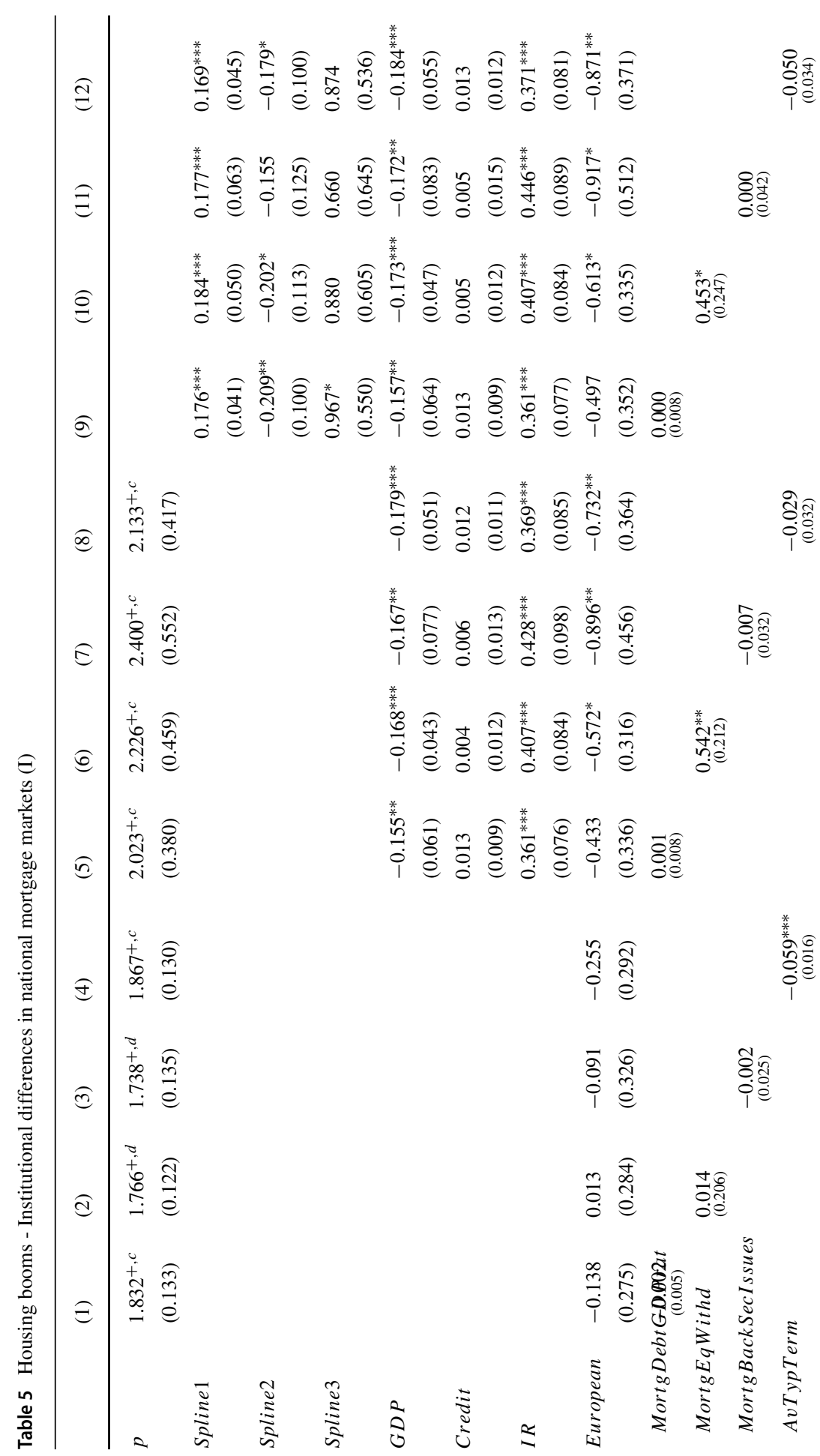




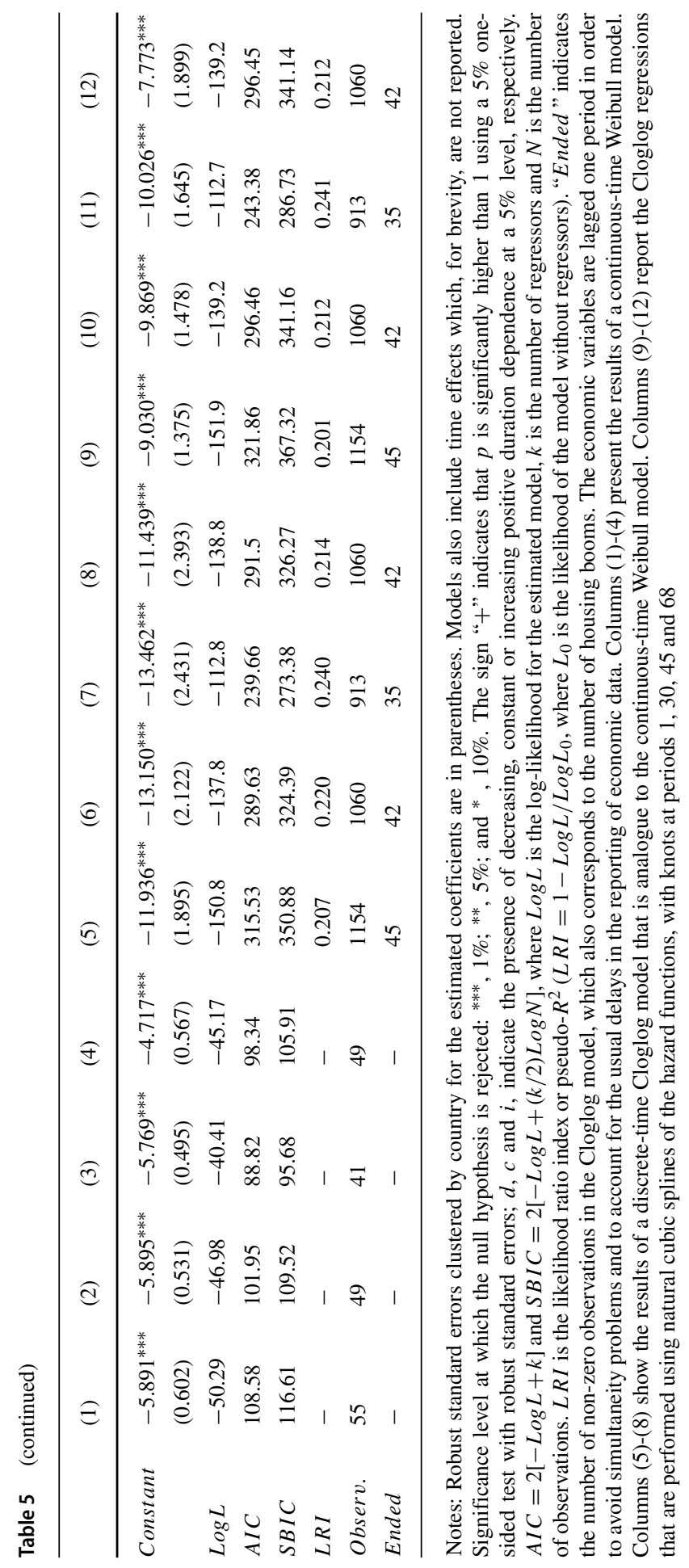




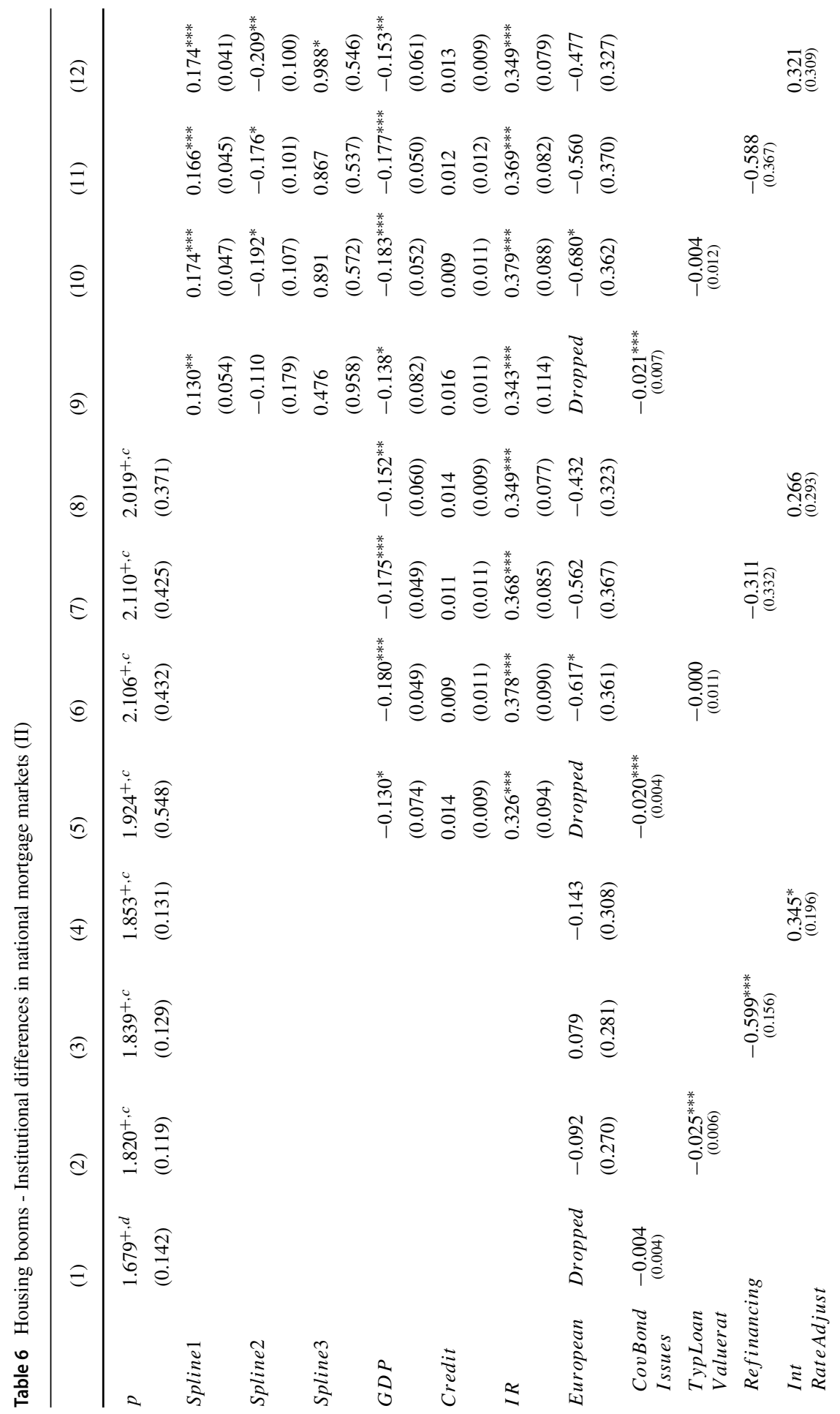




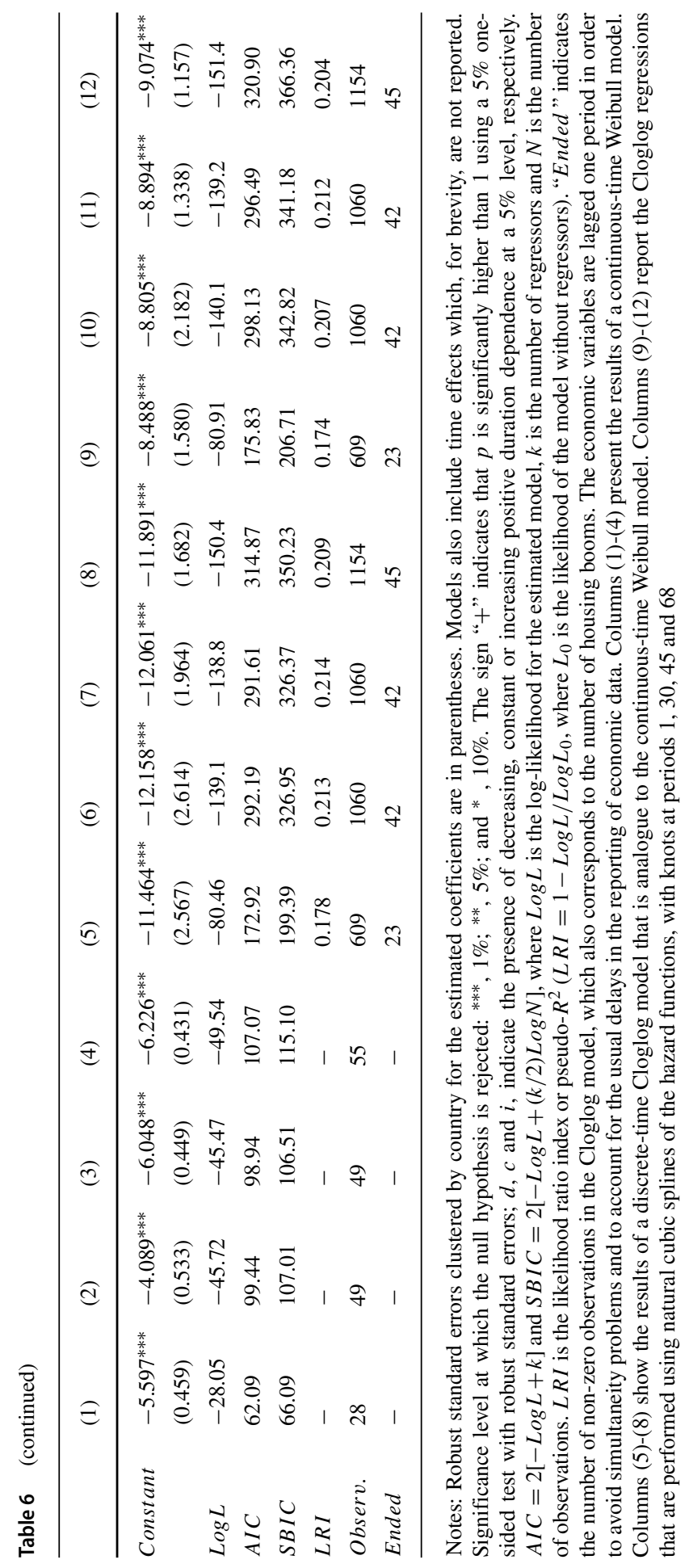




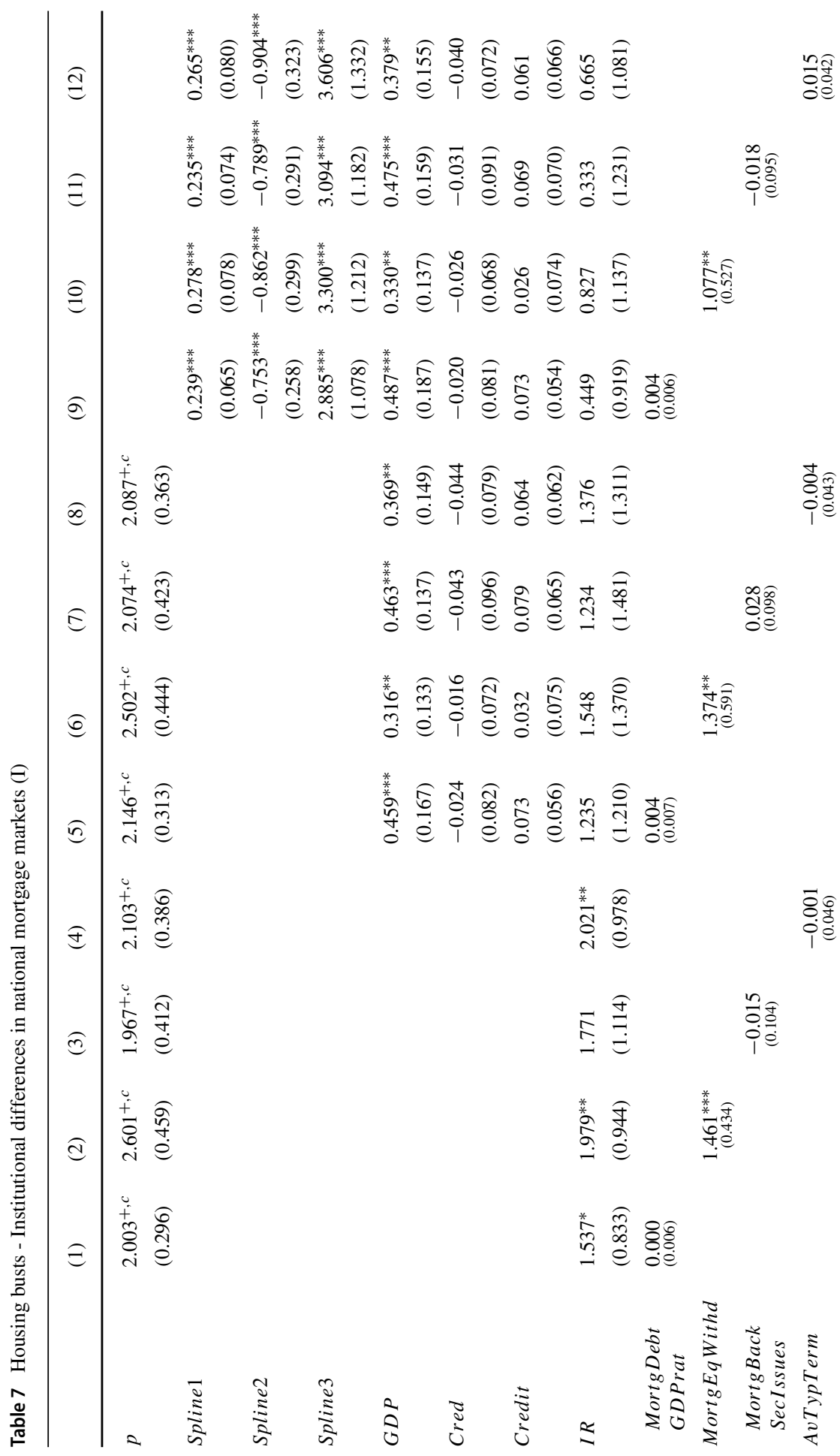




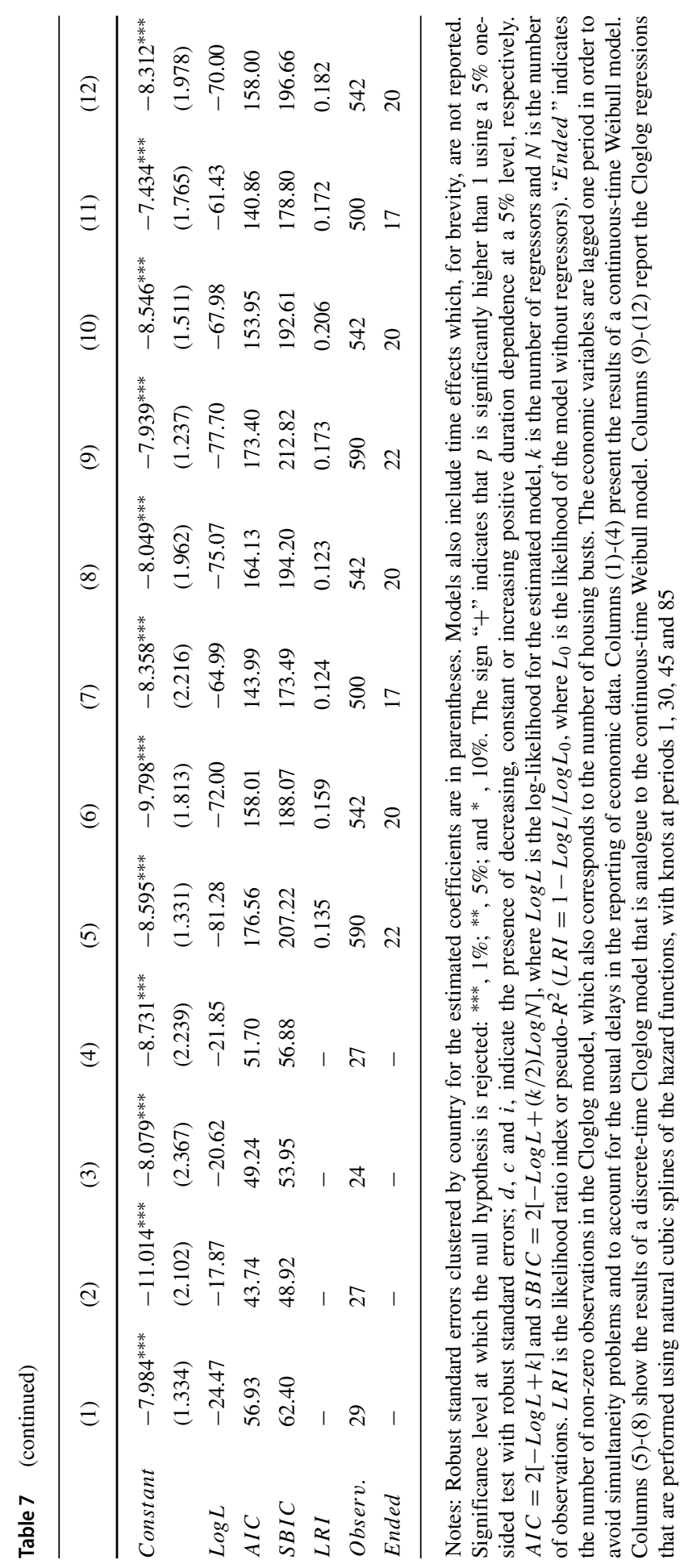




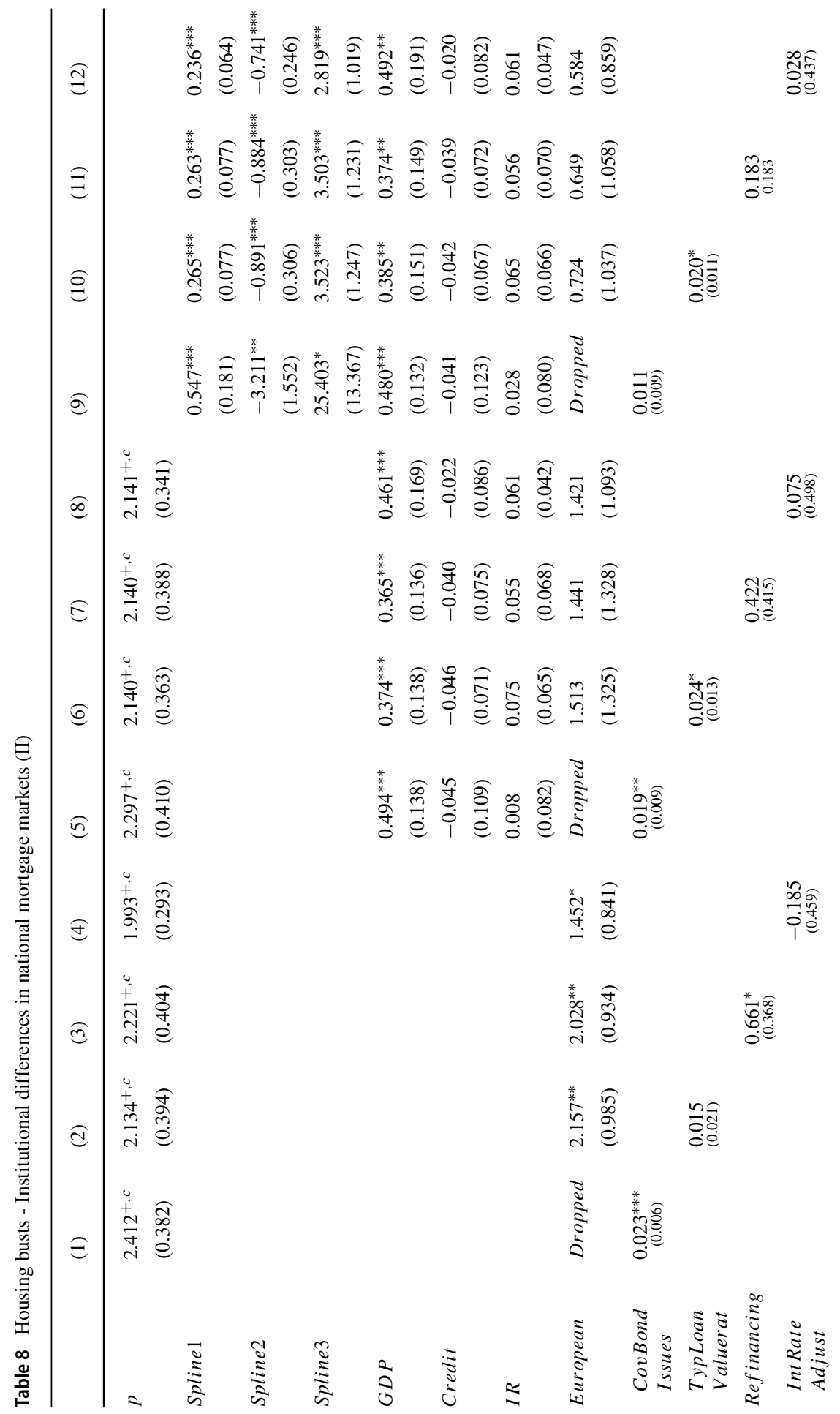




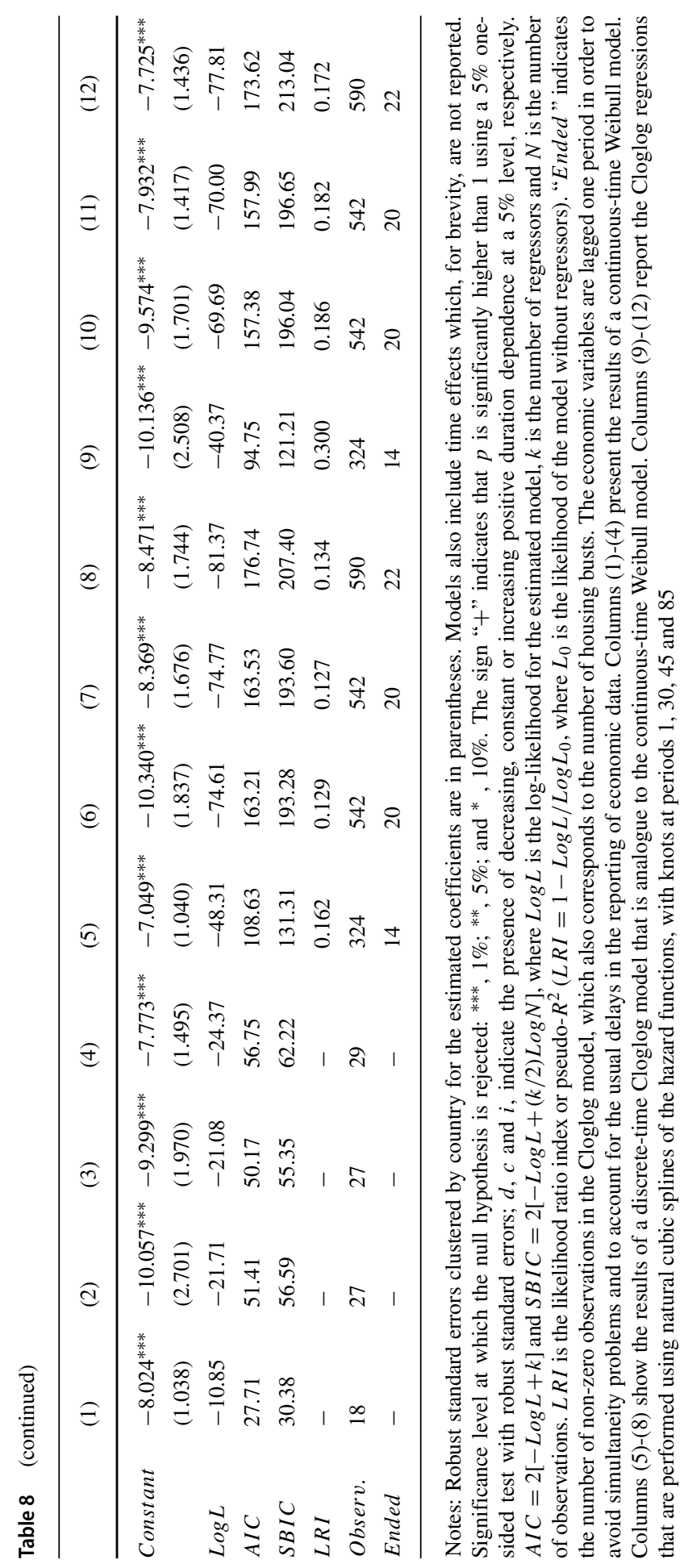




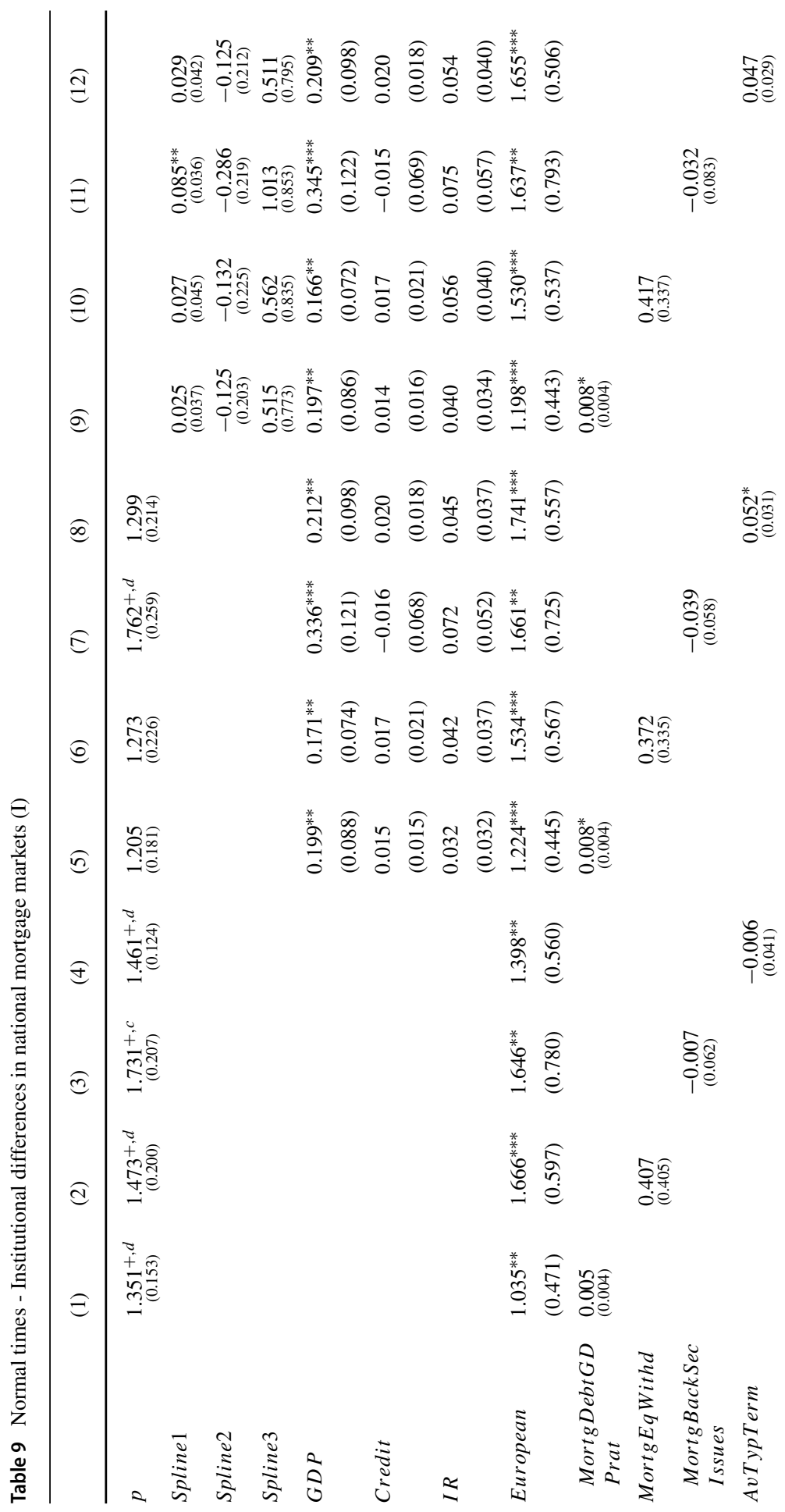




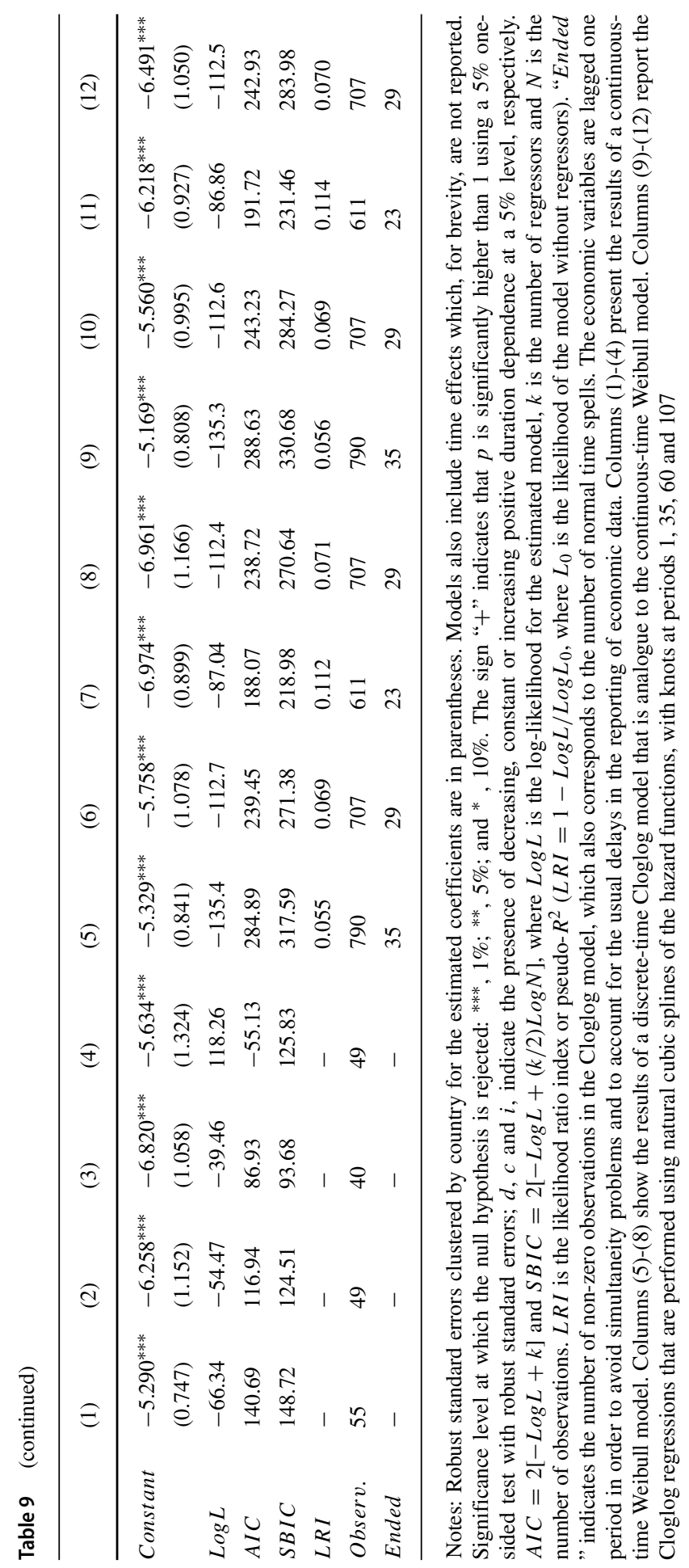




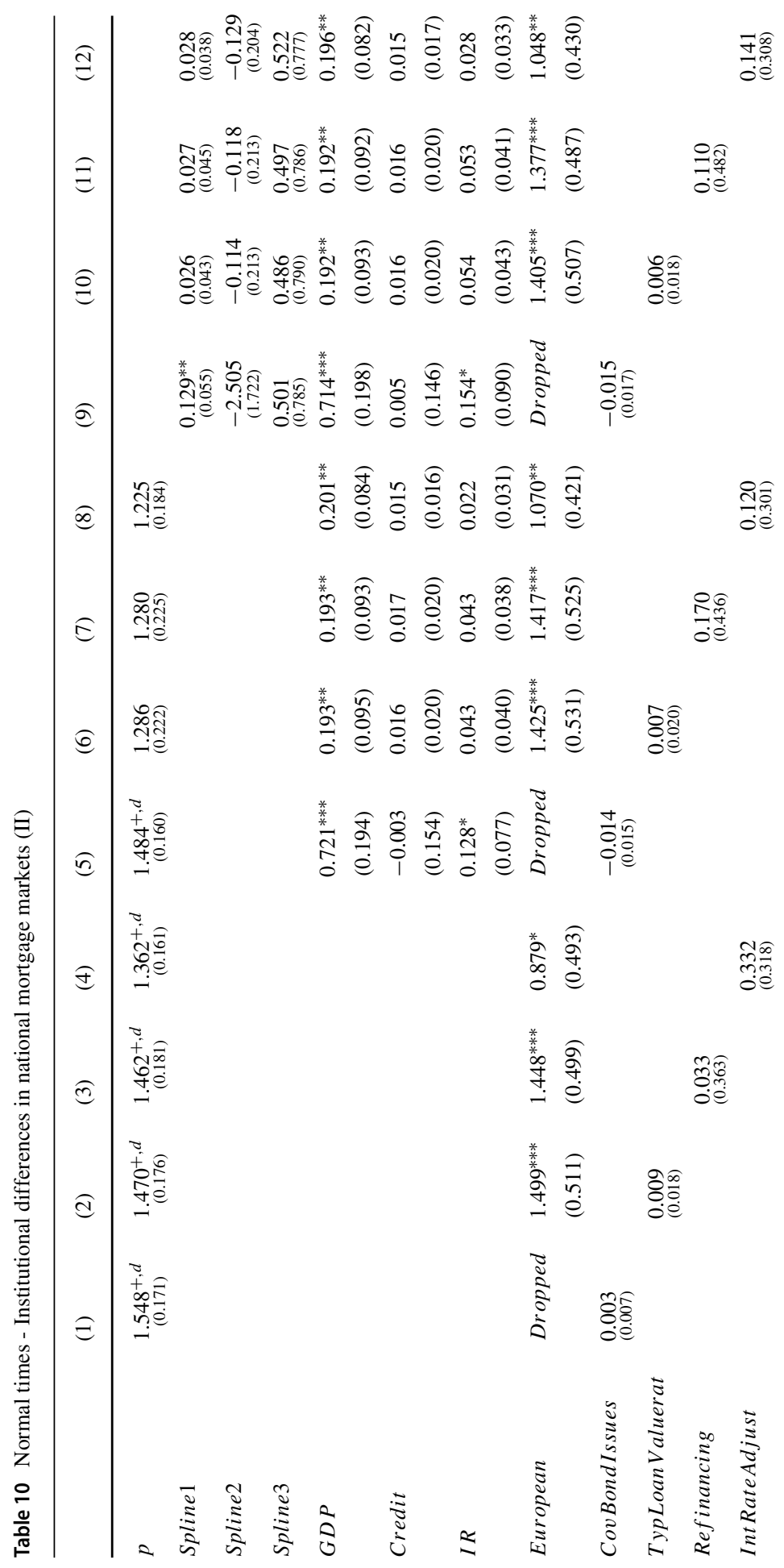




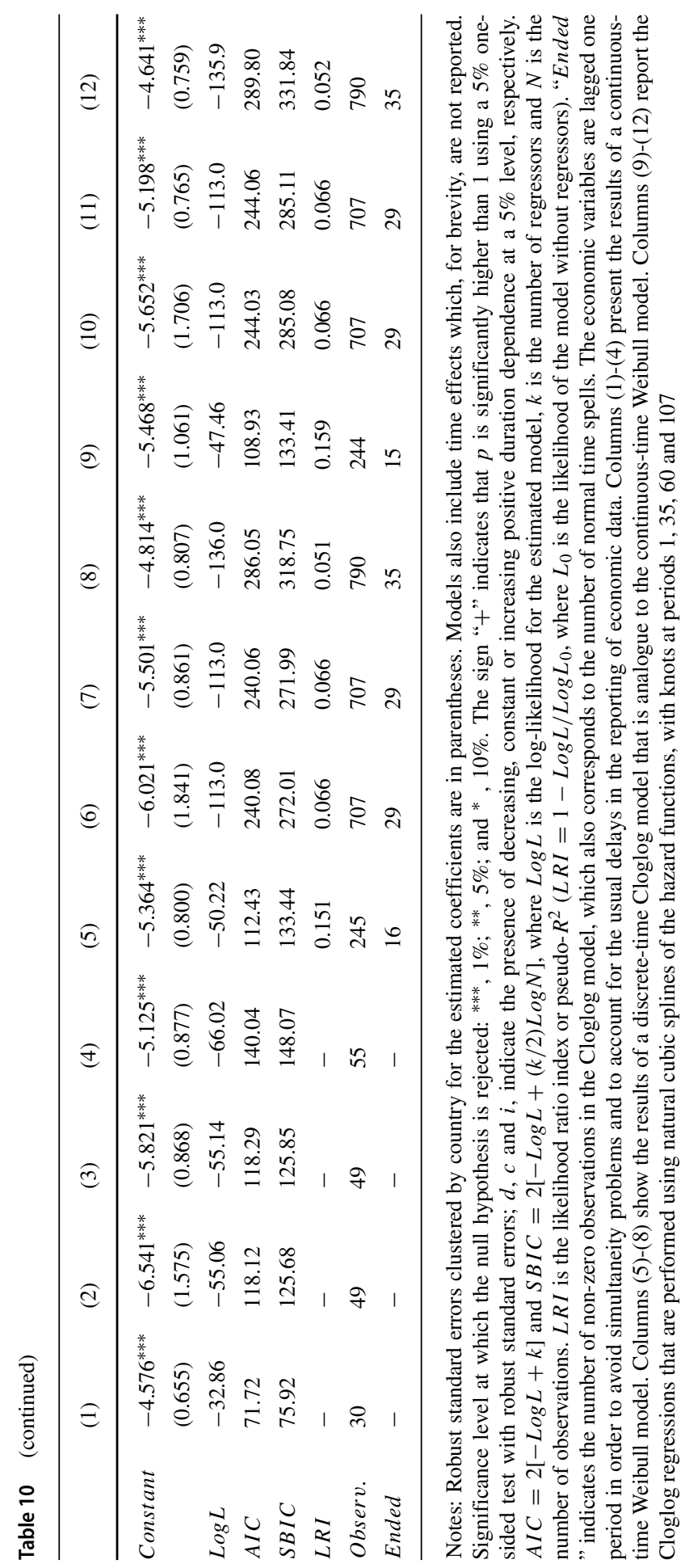


model. The absence of early repayment fees ease the ability of households to refinance their mortgage debt when interest rates fall. Thus the coefficient associated with Refinancing is negative.

All in all, the economic significance of certain housing finance characteristics for the duration of housing booms is of first-order importance: 1) a rise in the average typical term is associated with lower likelihood of the end of a housing boom by about 5.7\%; and 2) an increase in the loan-to-value ratio is linked with a reduction in the probability of a housing boom ending of close to $2.5 \%$.

Turning to housing busts (Tables 7 and 8), we find that, in line with the results for housing booms, mortgage debt-related indicators, such as Mortg DebtGD Prat and MortgBackSecIssues do not impact the duration of housing busts in a significant manner.

Interestingly, the possibility of mortgage equity withdrawals (MortgEqWithd) substantially reduces the duration of housing busts: the coefficient associated with this variable is positive and significant, thereby, suggesting that when house equity release products are available and/or permissible, the likelihood of the end of a housing bust increases. And net housing wealth remains somewhat resilient when households can borrow against accumulated housing equity.

In what concerns the average typical term (AvTypTerm), the empirical findings do not reveal any significant impact on the duration of housing busts. Thus, increasing the affordability of debt service payments by extending the duration of repayment periods does not help to dampen the length of housing busts.

The evidence also shows that the issuance of covered bonds (as percentage of residential loans outstanding) (CovBondIssues) tends to contribute to shorter housing bust episodes, as the coefficient associated with this variable is positive and significant. This result is in accordance with the observation that greater development of the secondary market for mortgage loans goes hand in hand with easier tap funding for lenders in the capital markets, which reduces the likelihood of a prolonged downturn in the housing markets.

As for the typical loan-to-value ratio (TypLoanValuerat), we find that it has a weakly significant impact on the duration of housing busts. In particular, an increase in the loan-to-value ratio raises the probability of the end of a housing bust, but only at the $10 \%$ significance level and only in the case of the discrete-time duration models. Thus, although larger loan-to-value ratios are positively correlated with home ownership rates, this indicator does not appear to play a key role in explaining the duration of housing busts.

Finally, the absence of early repayment fees (Refinancing) only weakly affects the duration of housing busts. Indeed, this variable is only significant at the $10 \%$ level in the case of the Weibull duration model, which shows that the possibility of refinancing is of secondary importance vis-a-vis the length of housing bust episodes. A similar conclusion emerges when we consider the degree of the interest rate adjustment (Int RateAdjust), which is never statistically significant throughout the various duration models analyzed.

Summing up, specific housing finance features play a key role in the determination of the length of housing busts, namely: 1) the possibility of mortgage equity withdrawals is linked with a two- to three-fold increase in the odds of a housing 
bust ending; and 2) a one percentage point increase in the issuance of covered bonds (as percentage of residential loans outstanding) is associated with an increase the likelihood of a housing bust ending by about $2 \%$.

In Tables 9 and 10, we consider the case of normal times in the housing market cycle. The results are clear: the large majority of the indicators that capture the institutional differences in national mortgage markets is not statistically significant. The two major exceptions are as follows. First, we find that the mortgage debt to GDP ratio (Mortg DebtGD Prat) has a positive and significant coefficient - even though only at a $10 \%$ level and in the case of the discrete-time duration models - on the length of normal times. Thus, an increase in that ratio leads to a shorter periods of normal times in the housing markets, which is consistent with the idea that high levels of indebtedness and excessive credit growth tend to generate housing booms. More specifically, a one percentage point in the mortgage debt to GDP ratio raises the likelihood of a normal time spell ending by close to $1 \%$. Second, the average typical term in years (AvTypTerm) is positive and significant at the $10 \%$ level, but only in the discrete-time duration model that is analogue to the Weibull model. Thus, there is some evidence suggesting that longer loan maturities can shorten the duration of normal times, propelling the switch to a period of housing boom. In particular, a one year increase in the average typical term leads to an increase in the probability of the end of normal times in the housing market of around 5\%.

In a nutshell, these results show that although some of the housing finance characteristics can significantly impact on the duration of housing booms and housing busts, the length of normal times depends more crucially on the economic fundamentals, as reflected in the output growth and, to some extent, the lending rates. As Cerutti et al. (2015) suggest, a higher degree of development of mortgage markets are associated with a higher frequency of real estate booms, thus, increased crisis risks. In the same spirit, Leung and $\mathrm{Ng}$ (2018) emphasize the existence of an intensified link between the housing sector and financial variables since the global financial crisis, despite a more muted response of the housing market to macroeconomic developments over the same period. In this context, macro-prudential policies and housing finance regulation may be particularly adequate to deal with mortgage market booms.

\section{Government Participation in Housing Finance}

In this Section, we analyze the impact of government participation in housing finance on the duration of the different phases of the housing market cycle. Tables 11, 12, 13 (housing booms) 14, 15, 16 (housing busts) 17, 18 and 19 (normal times). Columns 1-3 present the findings for the continuous-time (Weibull) duration model. Columns 4-6 report the results for the discrete-time (Cloglog) model that is analogue to the continuous-time Weibull model. Columns 7-9 show the Cloglog regressions using natural cubic splines of the hazard functions.

The empirical evidence presented in Tables 11 and 13 reveals that government participation in housing finance has only a weakly significant impact on the length of housing booms. In particular, we find that the coefficient associated with Gov ParticIndex is negative and significant - which implies that stronger government participation in housing finance is associated with longer housing booms - but 







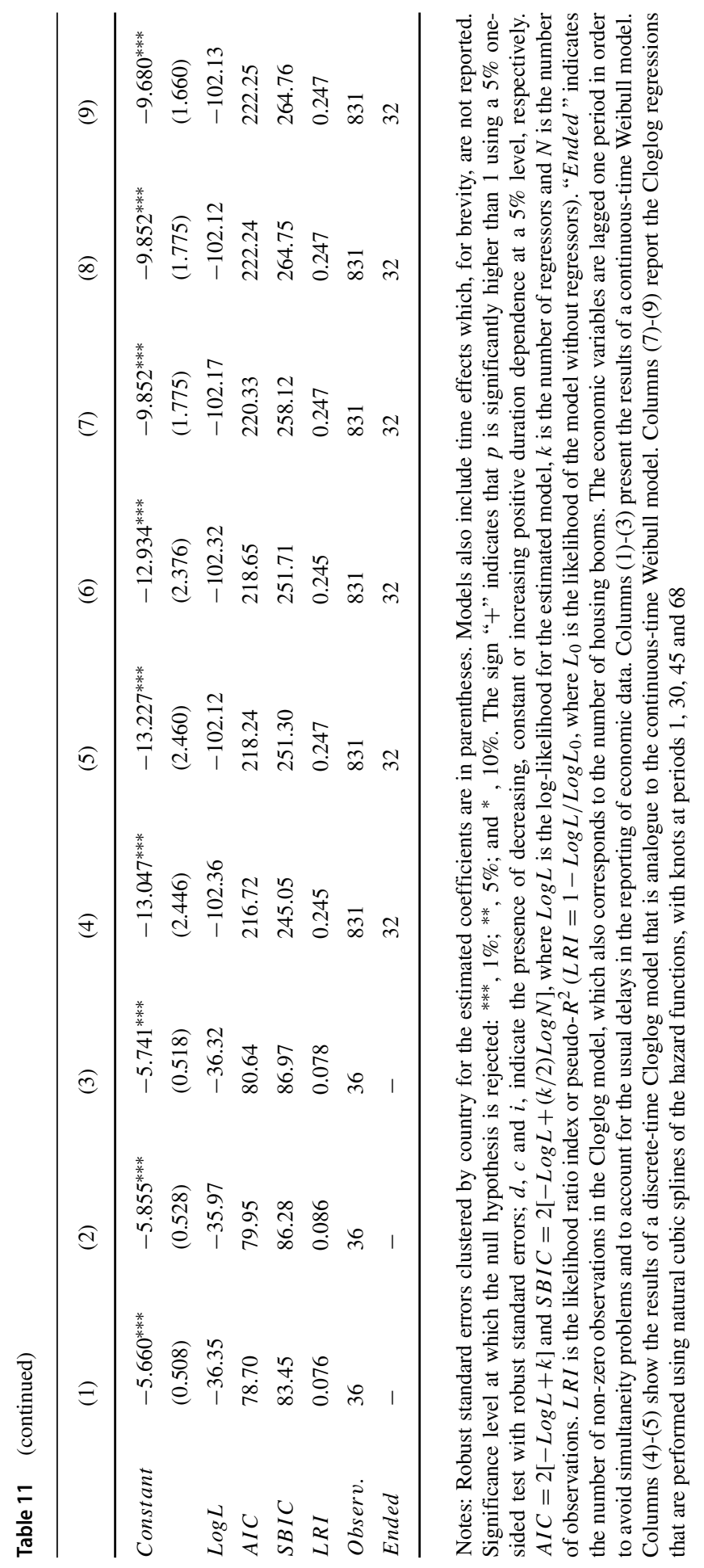




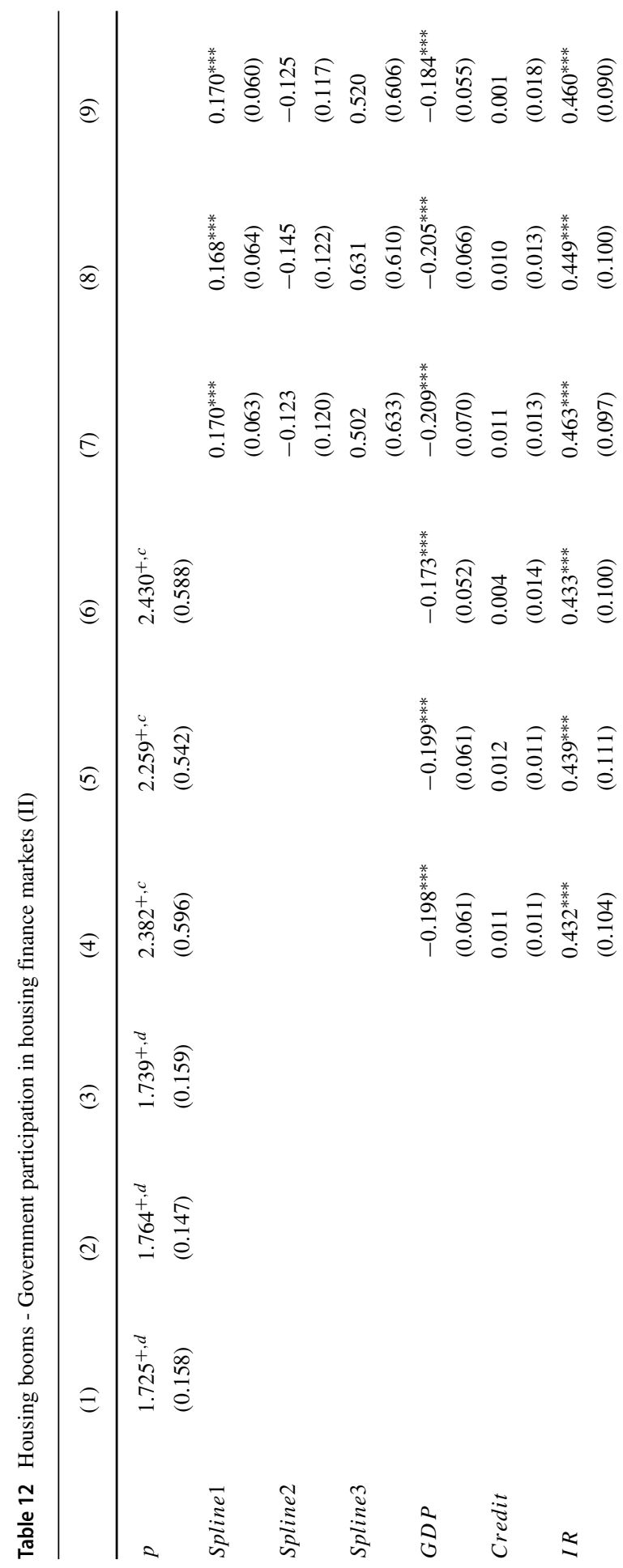




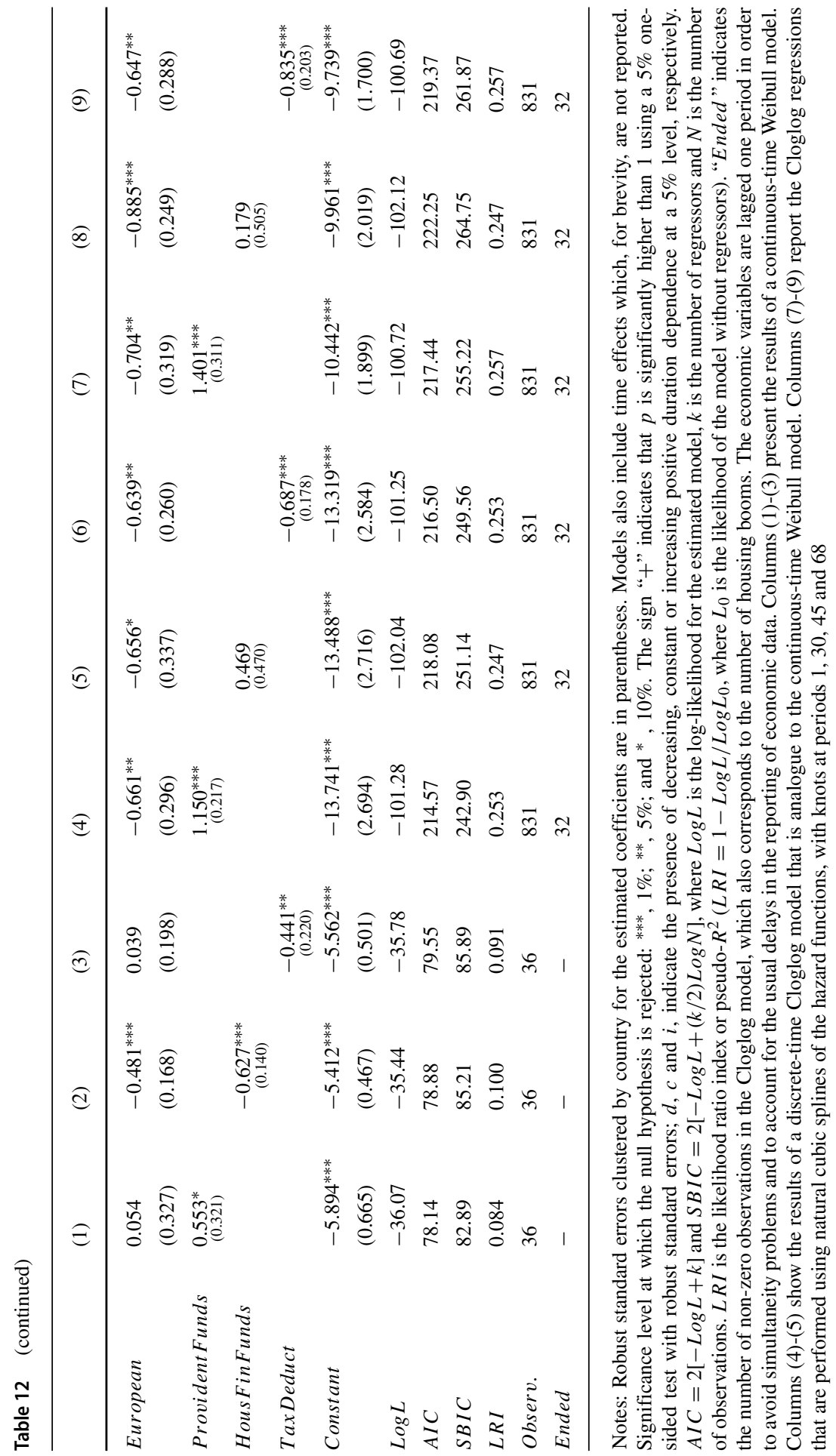




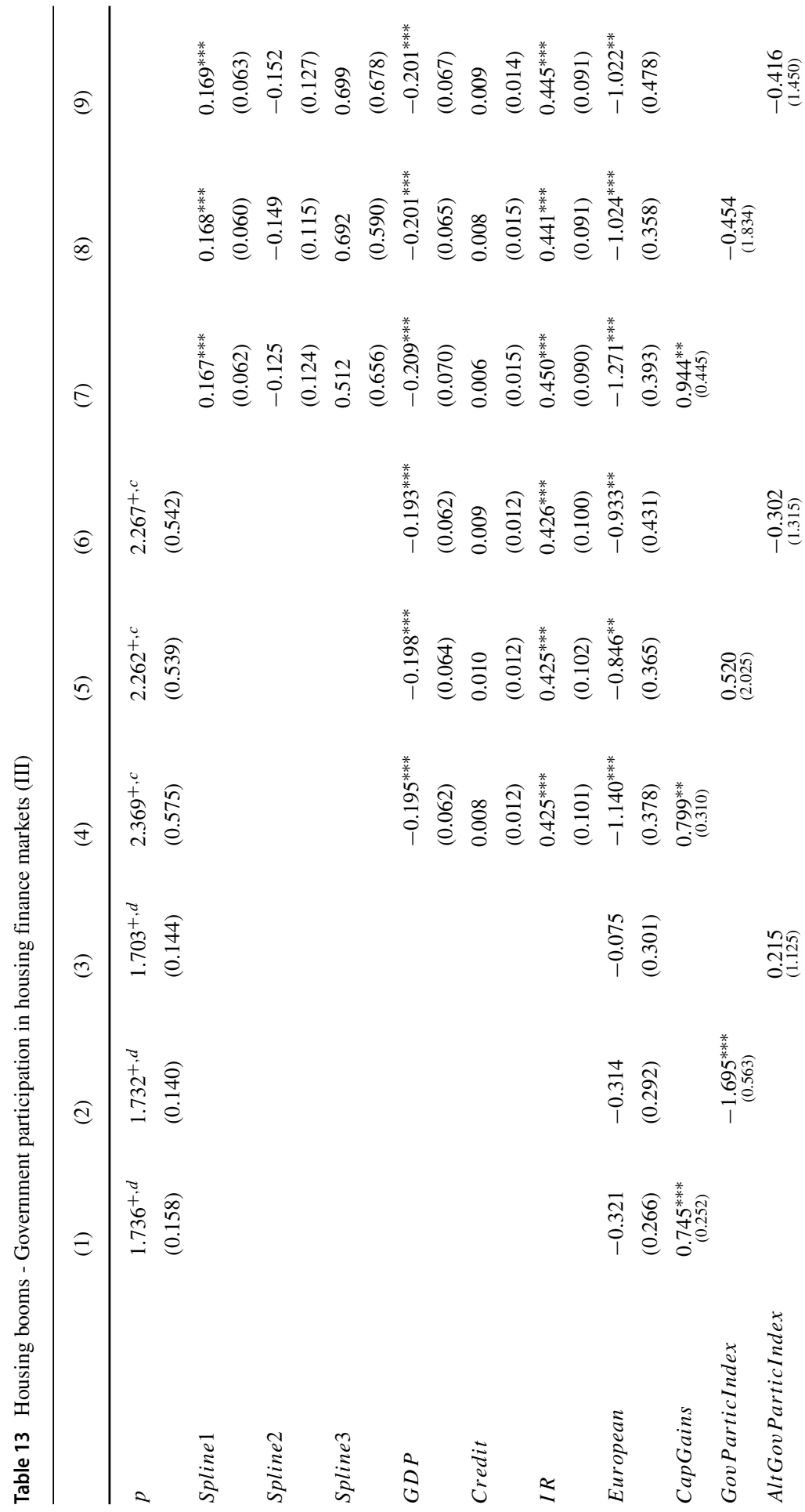




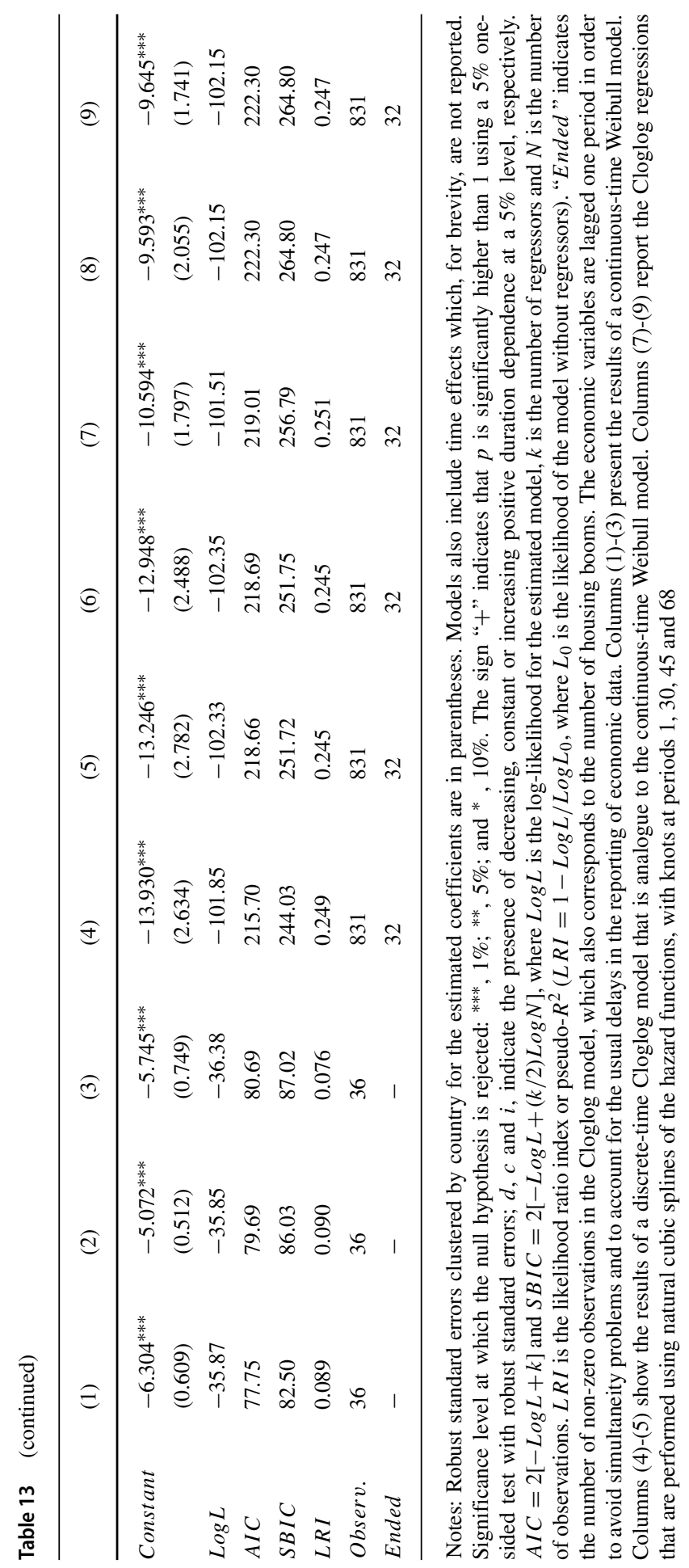




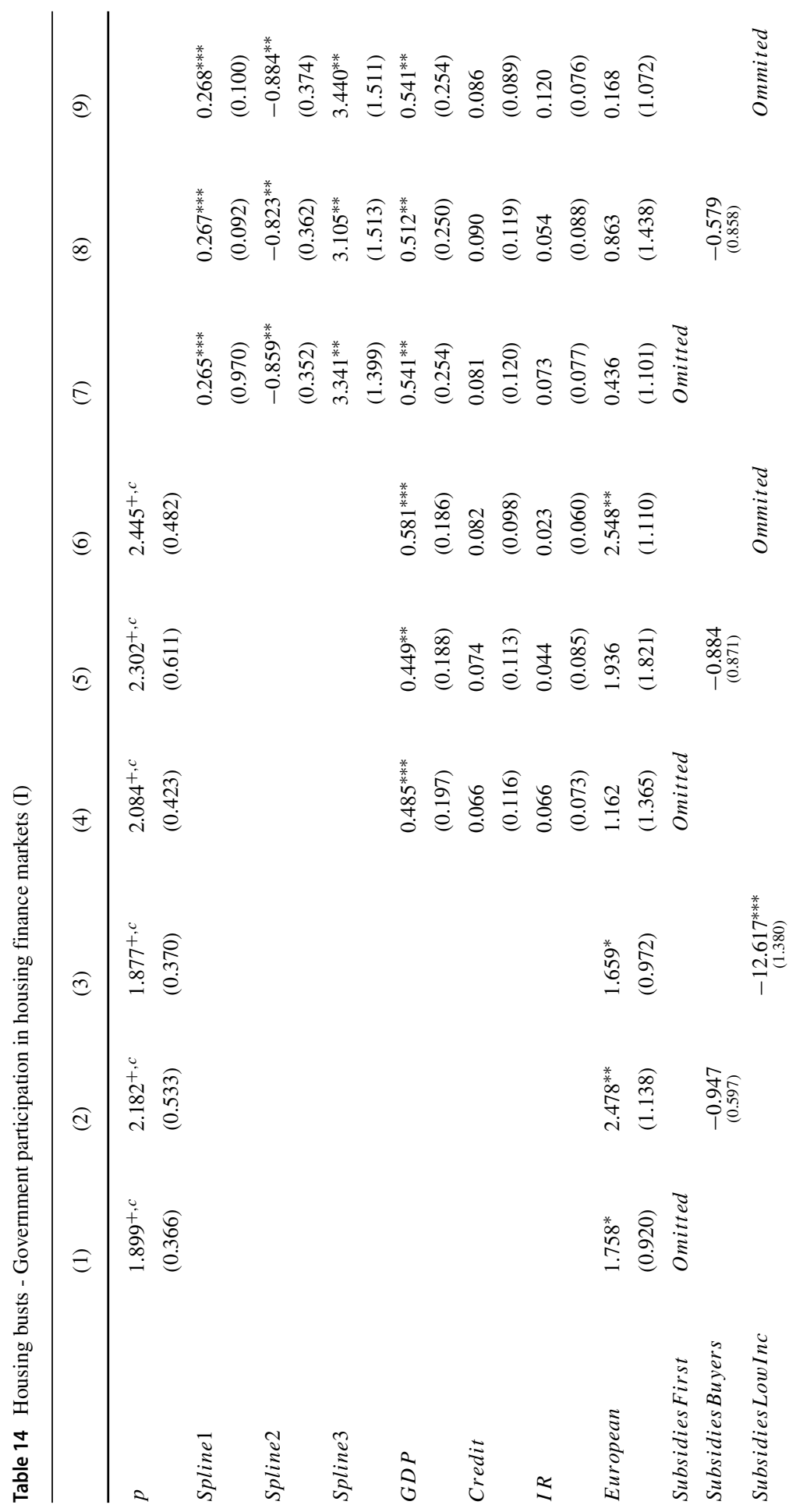




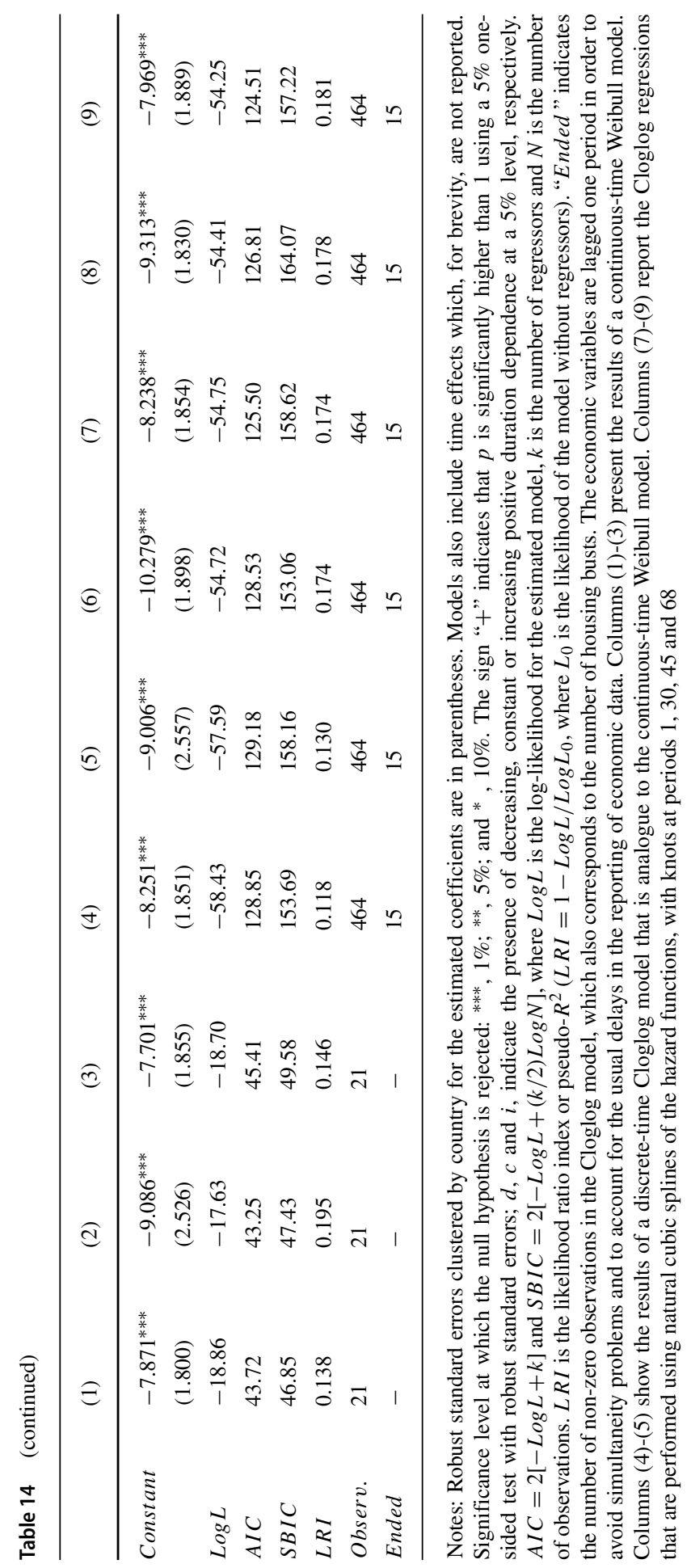




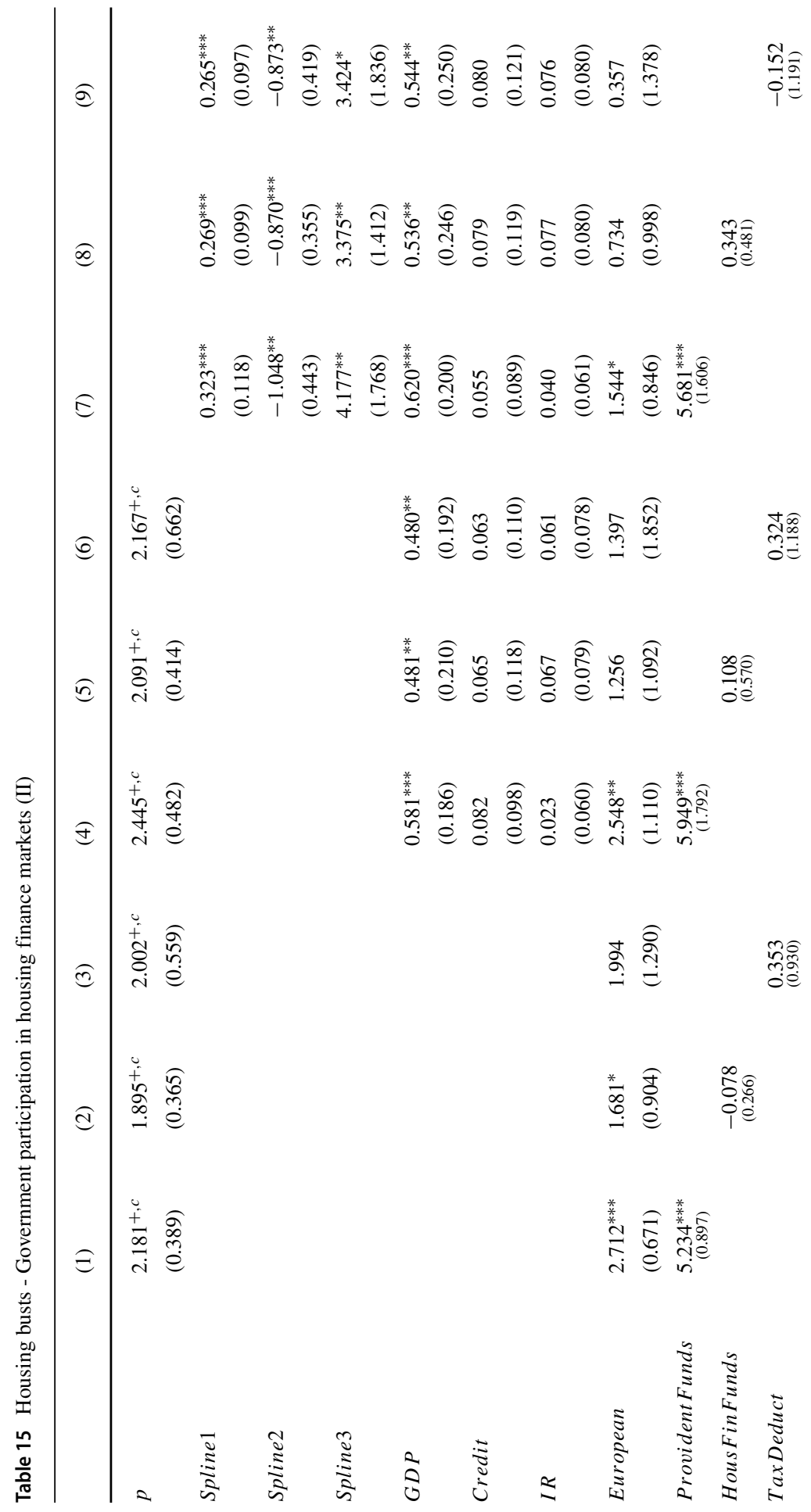




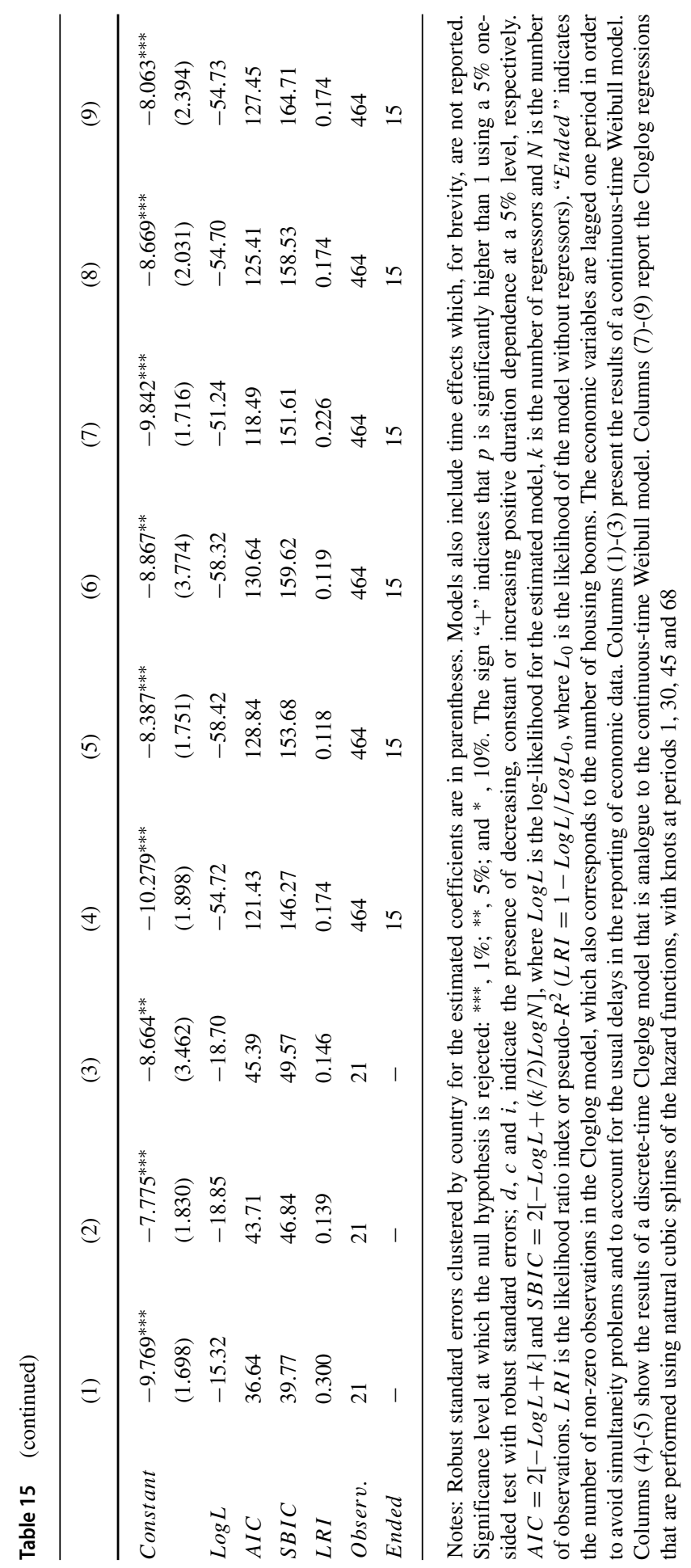




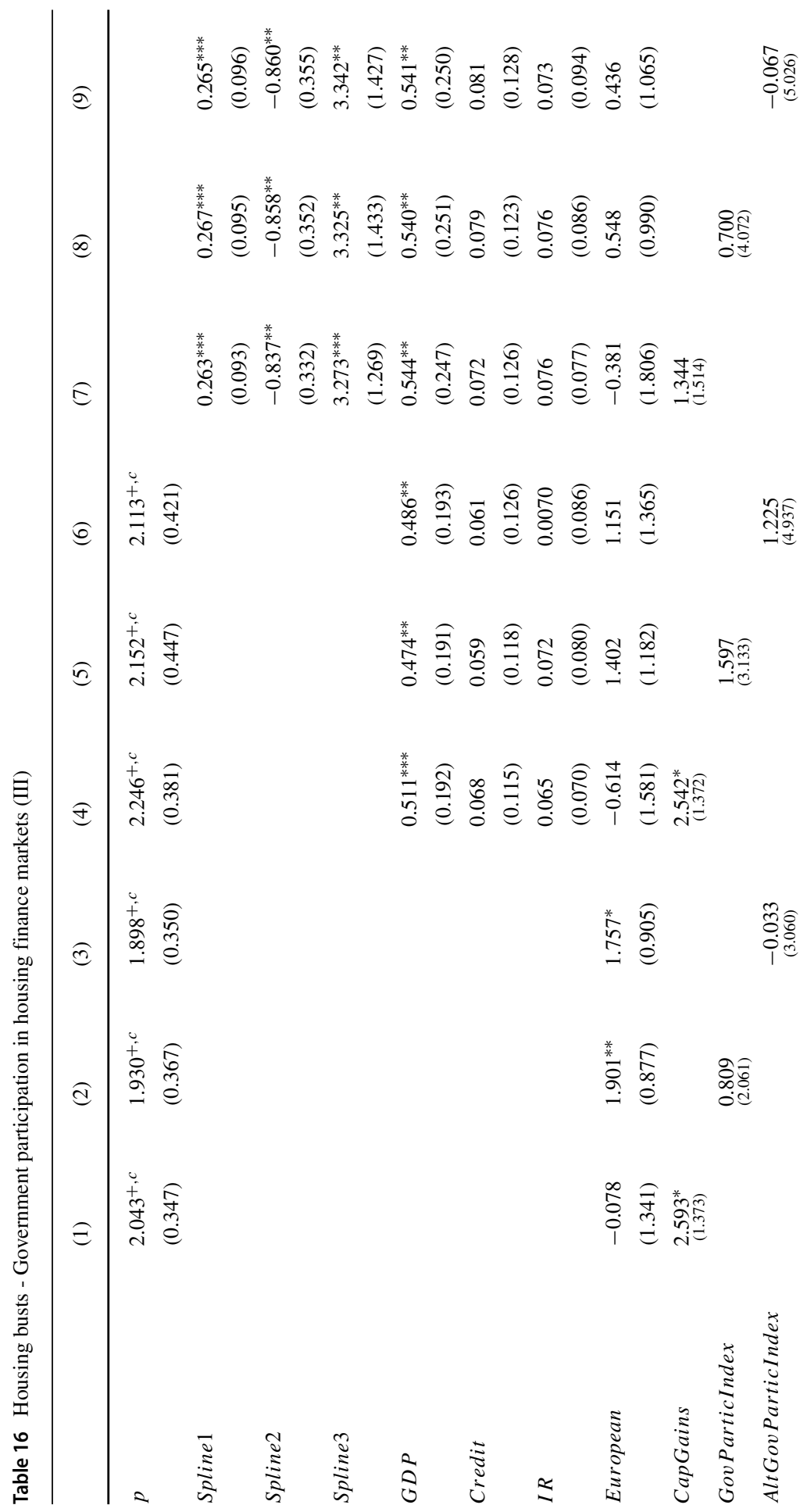




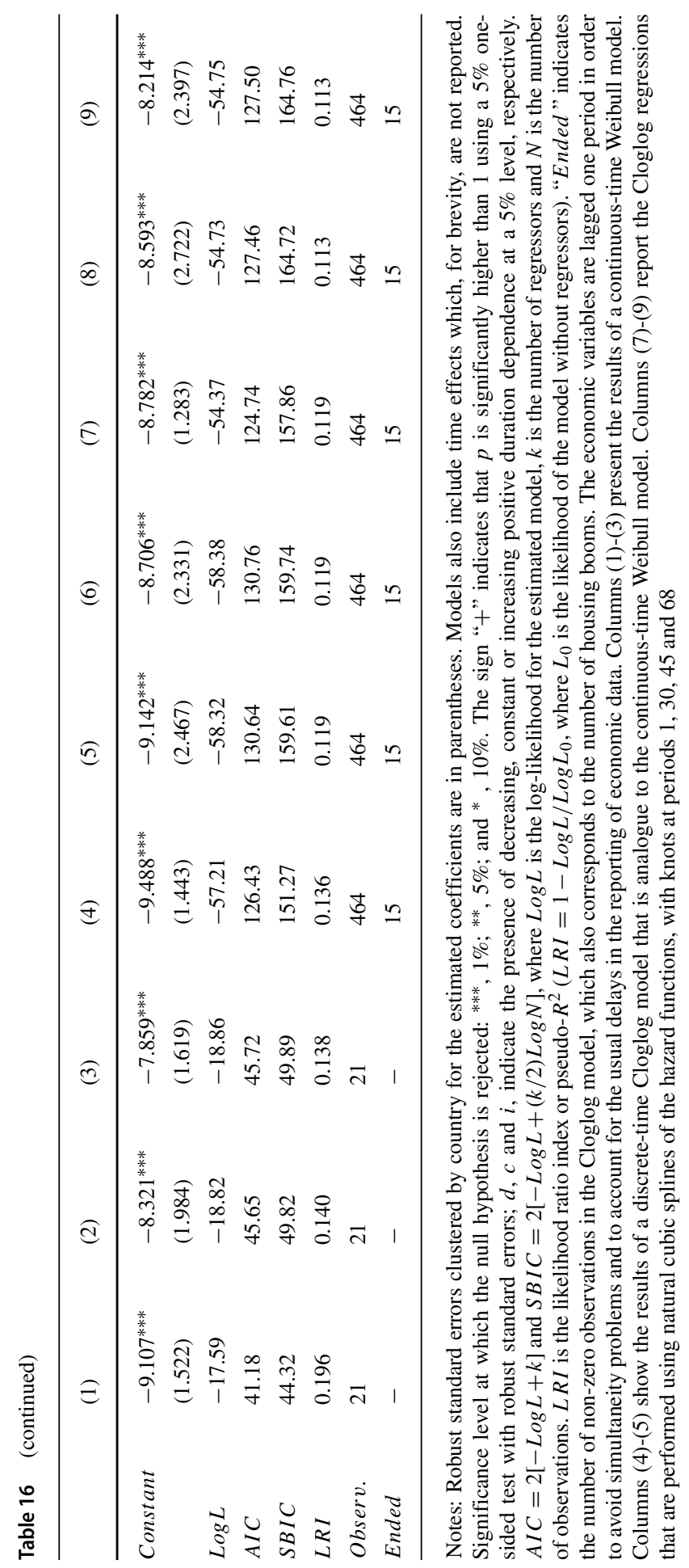




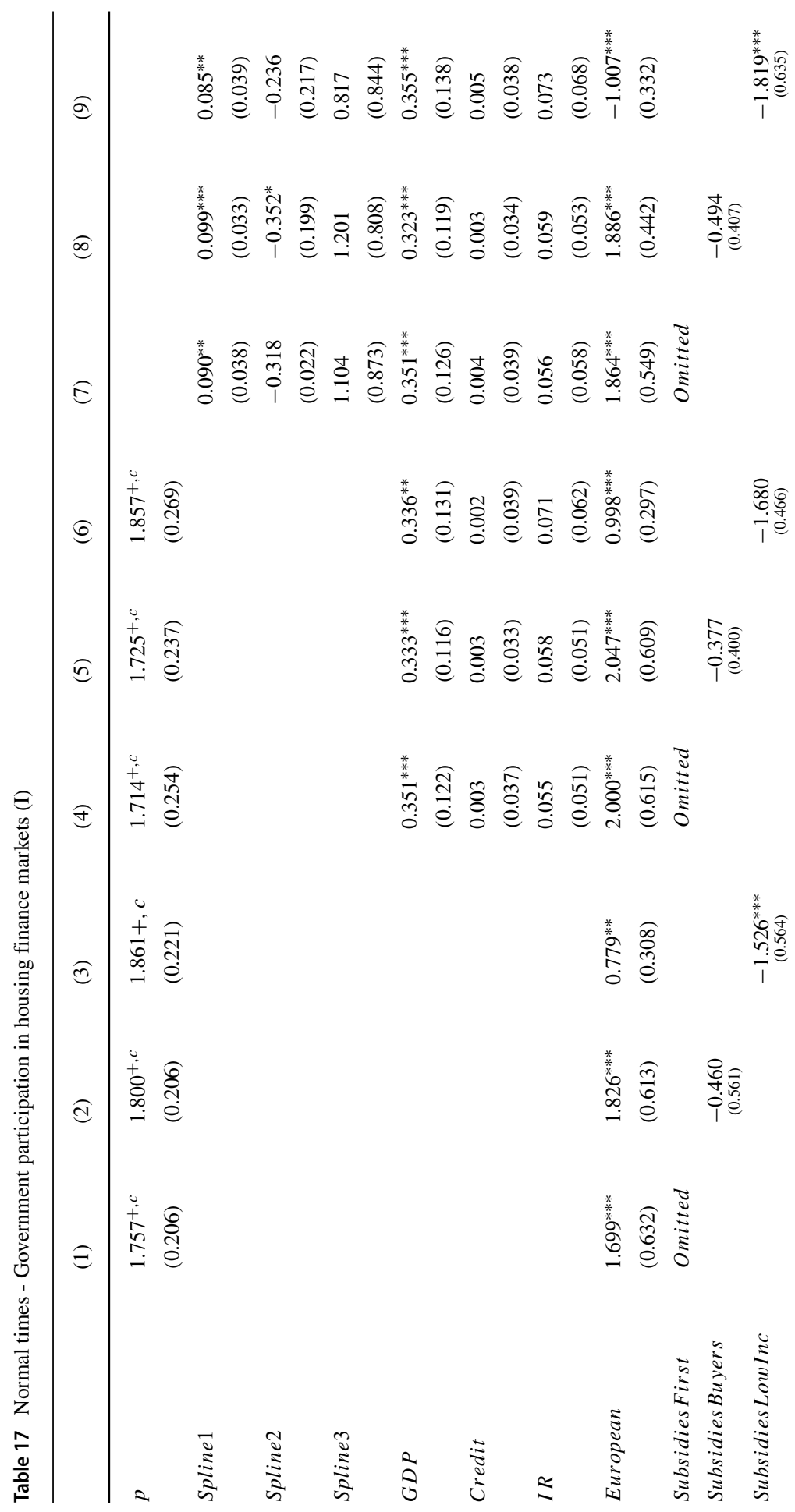




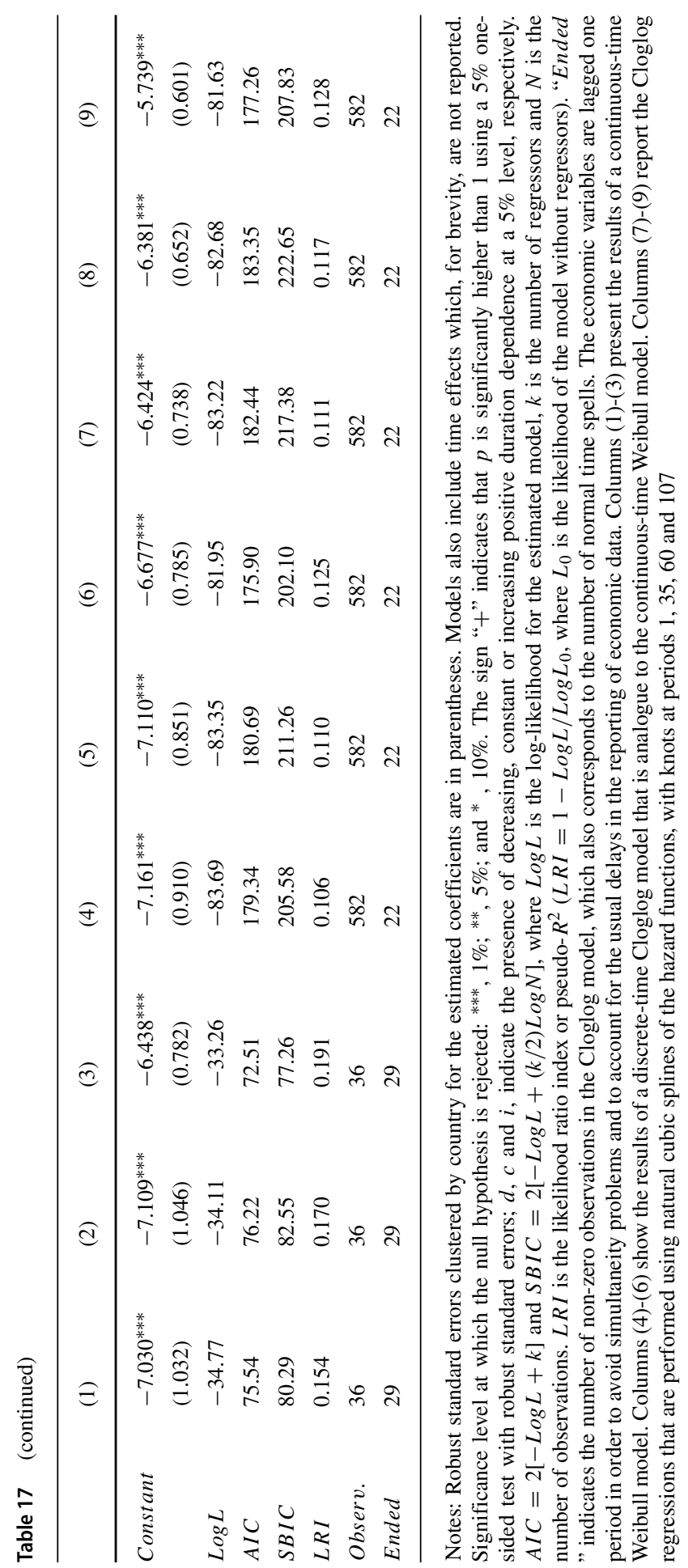




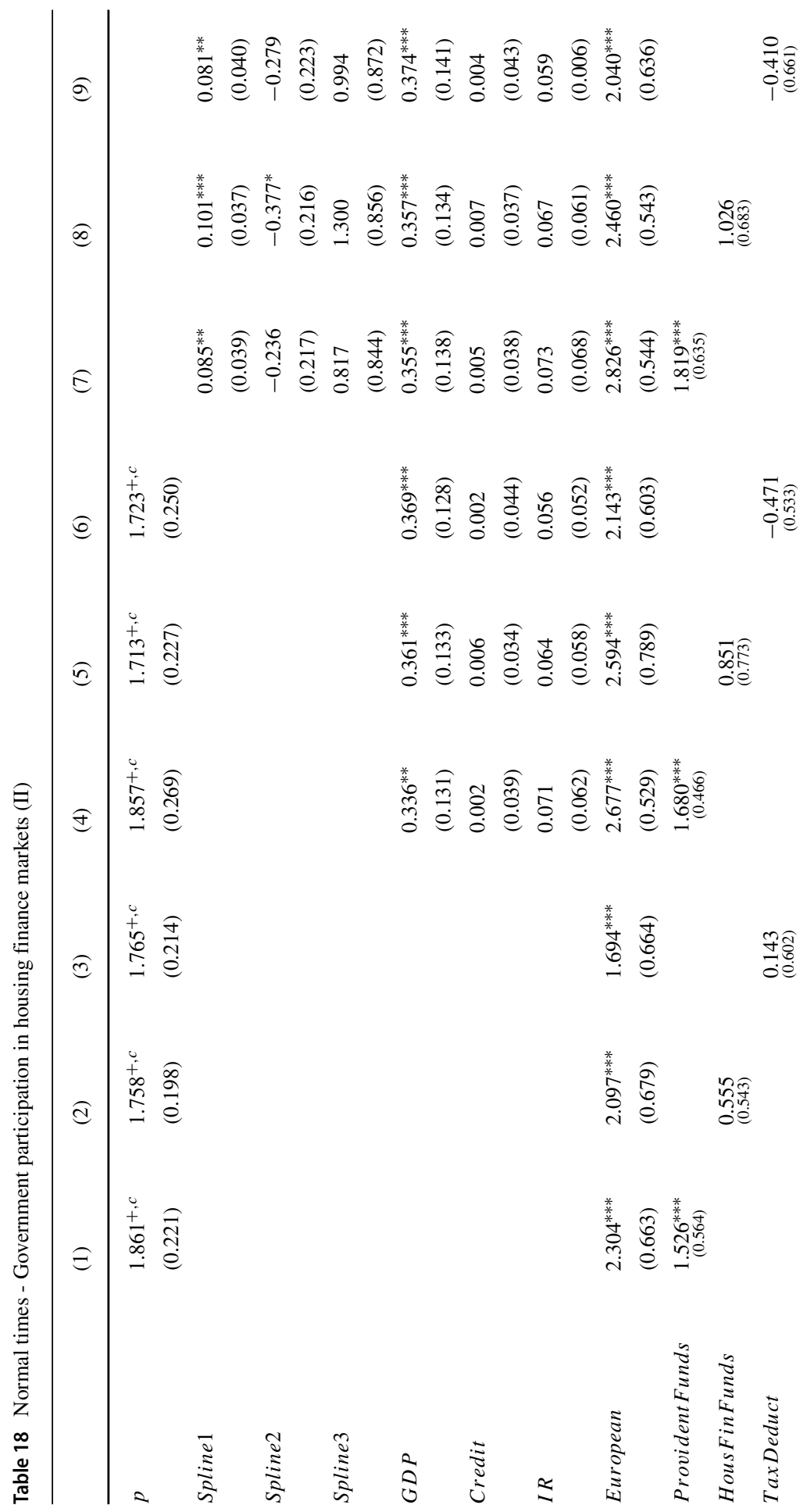




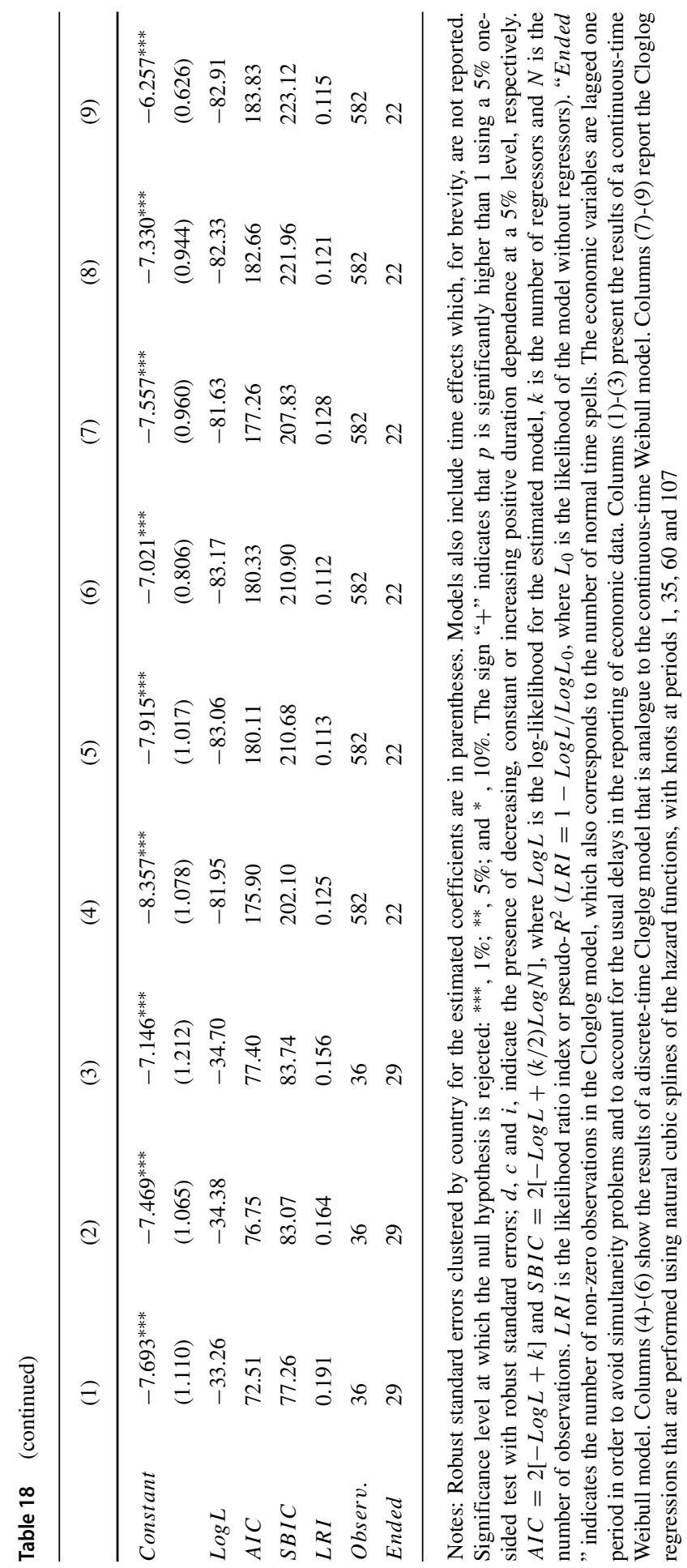




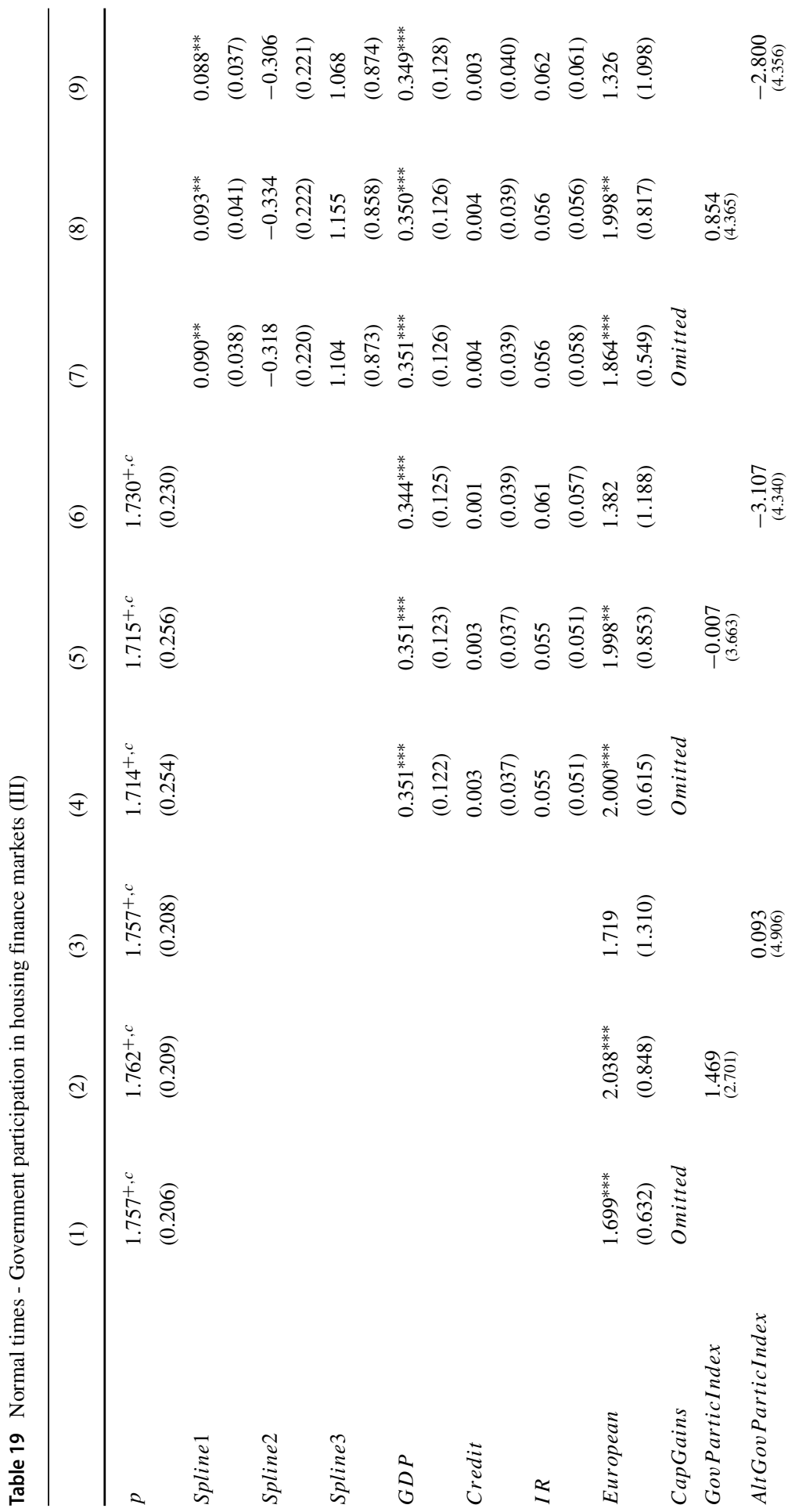




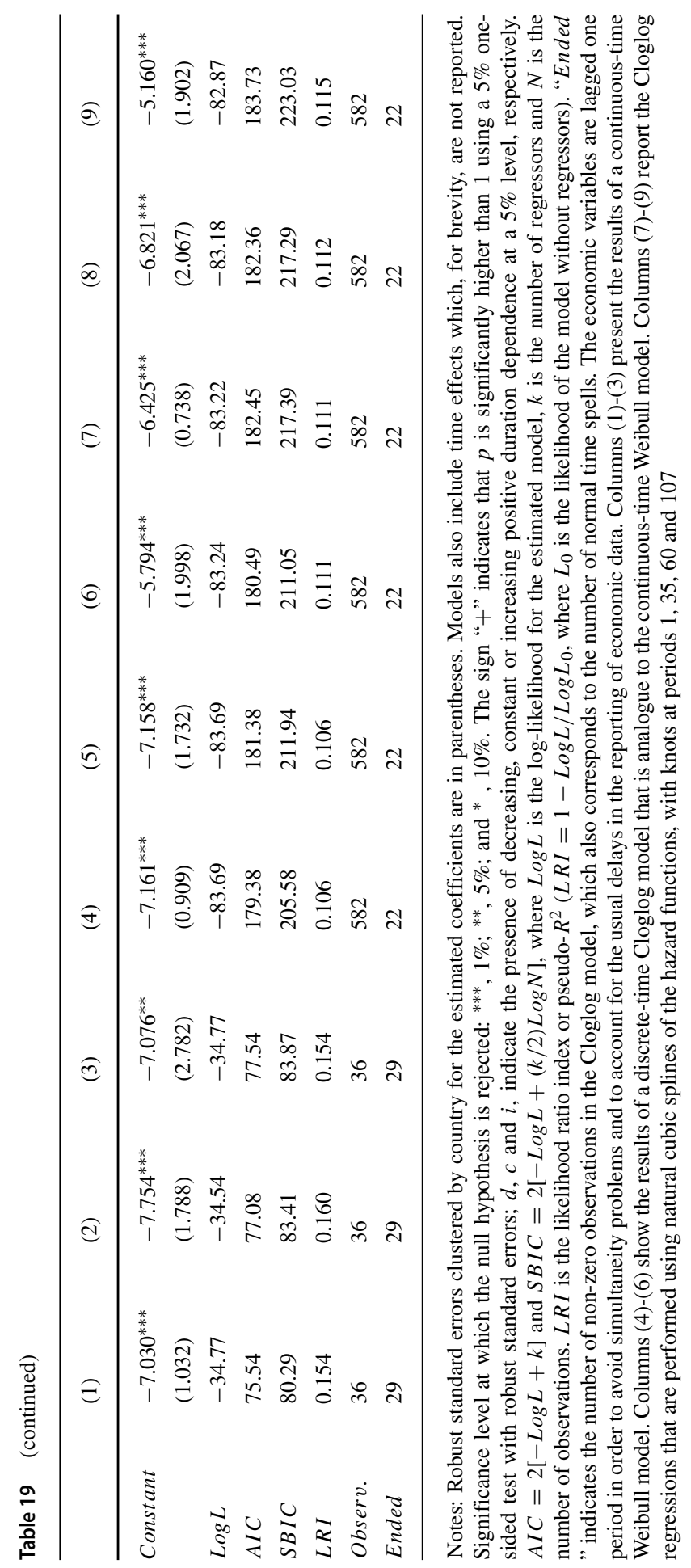


only in the case of the continuous-time duration model. In this case, a one point rise in the index of government participation is associated with a reduction of the the likelihood of a housing boom ending of, approximately, $81.6 \%$.

When we consider the sub-dimensions of the government participation index, some interesting results emerge. More specifically, the duration of housing booms is significantly prolonged in the presence of tax deductibility of mortgage interest (Tax Deduct), but housing booms are significantly shorter when capital gains are tax deductible (CapGains). Even though the distributional impact of tax deductibility is complex in nature, the former form of government support is more likely to favour low-income and liquidity-constrained households than the latter, which tends to benefit more wealthy households (IMF 2009, 2011; OECD 2011). Using US data, Ellis (2008) also finds that tax deductibility of mortgage interest in the absence of prepayment penalties can promote higher household indebtedness via cash-out refinance re-mortgaging. This can, in turn, fuel house price growth.

Housing booms are also significantly shorter when provident funds' early withdrawals for housing purposes (ProvidentFunds) are possible. Additionally, the presence of housing finance funds or government agencies that provide guarantees/loans (HousFinFunds) weakly affects the length of housing booms, as the effect is only significant in the case of the continuous-time duration model. Interestingly, the coefficients associated with Provident Funds and Hous Fin Funds differ in terms of sign, being positive for the former and negative for the latter. This means that while government support measures aimed at providing liquidity to the mortgage market limit the occurrence of housing booms, those that originate mortgage loans tend to increase the likelihood of periods of fast house price appreciation. Thus, an unintended consequence of government participation in housing finance is that the provision of guarantees or mortgage loans can exacerbate house price upward swings.

Finally, the existence of subsidies to buyers through savings account contributions or through preferential fees (Subsidies Buyers) has only a significant impact in the case of the continuous-time duration framework.

In what concerns the duration of housing busts, the empirical results summarized in Tables 14 and 16 do not support a statistically significant role for government participation in housing finance. This shows that greater government involvement in the housing market does not necessarily provide a cushion vis-a-vis large and long-lasting housing price downturns.

However, some dimensions of the government participation index appear to be crucial. For instance, we find that provident funds' early withdrawals for housing purposes (ProvidentFunds) are associated with shorter housing busts. Thus, the provision of liquidity to mortgage markets seems key for the reduction of the length of periods of large house price downturns.

A similar result is uncovered for tax deductibility of capital gains (CapGains), which favour more wealthier households, even though the effect is only significant at the $10 \%$ level. By contrast, subsidies to low-income groups (SubsidiesLowInc) tend to be linked with longer housing busts, which suggests that this type of social housing policy support can contribute to more persistent house price declines. This result is close in spirit with the work of Chiquier and Lea (2009), who show that, by stimulating (mortgage) credit growth, subsidized (mortgage) credit can be 
detrimental for financial stability. Thus, by lowering the cost of pre-crisis credit, government subsidization can pave way for an amplified housing price swing in downturns. No significant impact is uncovered for other types of housing subsidies.

Finally, as for normal times spells, the results shown in Tables 17 and 19 do not corroborate a significant impact of government participation in housing finance, as witnessed by the lack of significance of the coefficients associated with GovParticIndex and AltGov ParticIndex. This lends support to the idea that normal times are periods of alignment between housing prices and economic fundamentals. Thus, government support measures are, overall, of secondary importance vis-a-vis the general economic environment when it comes to shaping the length of this housing market cycle phase.

Looking at various dimensions of the government participation index, we find that subsidies to buyers through savings account contributions or through preferential fees (Subsidies Buyers) do not significantly affect the length of normal time spells. By contrast, the coefficient associated with housing subsidies to low-income groups (SubsidiesLowInc) is negative and statistically significant. Thus, an increase in up-front subsidies to such households increases the duration of normal times of the housing market and suggests a policy bias in favour of this group of potential home buyers.

Additionally, early withdrawals (for housing purposes) from provident funds are associated with shorter normal time spells, as the sign of Provident F unds is positive and significant. This highlights that excessive withdrawals from provident funds can accelerate the transition to boom-bust phases. Moreover, even though guarantees/loans provided by housing finance funds or government agencies (HousFinFunds) and tax deductibility of mortgage interest (TaxDeduct) enter the model with the expected signs, they do not significantly impact the duration of normal times.

\section{Conclusions}

In this paper, we use data for 20 OECD countries over the period 1970Q1-2015Q4 and rely on duration analysis to show that the liberalization of the mortgage sector induces longer housing booms, while a higher degree of securitization is associated with shorter housing busts.

Addressing the institutional differences in national mortgage markets, we also find that the length of housing booms and busts is especially responsive vis-à-vis changes in housing finance. In particular, the possibility of mortgage equity withdrawals, the average typical terms, the issuance of covered bonds and the loan-to-value ratio are relevant for the duration of housing booms and busts.

As for the government involvement in housing finance, the empirical evidence suggests that some dimensions of participation can affect the length of housing market cycle phases. More specifically, tax deductibility of mortgage interest (capital gains) is associated with longer (shorter) housing booms. Similarly, the provision of guarantees or loans (liquidity) by state-owned or state-sponsored financial institutions and finance agencies increases (reduces) the duration of housing booms. And while greater involvement by the government in the mortgage market does not 
necessarily cushion against housing busts, liquidity from provident funds is linked with lower likelihood of protracted house price declines.

All in all, our work suggests that macro-prudential policies (in particular, housing finance regulation) might shield against the deleterious macroeconomic impact of housing busts and financial stability risks posed by housing booms (Arslan et al. 2015a; Rubio and Carrasco-Gallego 2017; Kelly et al. 2017). Additionally, it emphasizes the role that monetary policy can play, namely, by affecting interest rates and avoiding (or reducing) the likelihood of housing booms (Arslan 2014; Chen et al. 2014). Moreover, as boom-bust cycles in the housing market are typically associated with the credit cycle, monetary policy can also be a key complement to macroprudential policies (Bailliu et al. 2015; Falagiarda and Saia 2017; Gelain and Ilbas 2017; Rubio and Carrasco-Gallego 2014). Finally, it shows that government participation in housing finance is not without unintended consequences. As a result, tax deductibility needs to be properly designed given its likely distributional impact. The "liquidity-provision" versus "loan-generation" trade-off embedded in some government support measures should also set the right balance between mitigating disruptions caused by housing slumps on the one hand, and avoiding fast house price appreciation on the other hand.

Acknowledgments We are grateful to one anonymous referee, the editor of this journal, the participants to the 3rd International Workshop on "Financial Markets and Nonlinear Dynamics" (FMND) and the 16th Annual Conference of the European Economics and Finance Society (EEFS), seminars at the Bank for International Settlements (BIS) and the Loughborough University, and to Joscha Beckmann, Claudio Borio, Giovanni Lombardo, Sushanta Mallick, Christopher Spencer, Kostas Tsatsaronis and Justine Wood, for their constructive comments and suggestions that considerably improved this paper.

Open Access This article is distributed under the terms of the Creative Commons Attribution 4.0 International License (http://creativecommons.org/licenses/by/4.0/), which permits unrestricted use, distribution, and reproduction in any medium, provided you give appropriate credit to the original author(s) and the source, provide a link to the Creative Commons license, and indicate if changes were made.

\section{References}

Agnello, L., \& Schuknecht, L. (2011). Booms and busts in housing markets: Determinants and implications. Journal of Housing Economics, 20(3), 171-190.

Agnello, L., Castro, V., Sousa, R.M. (2013). What determines the duration of a fiscal consolidation program? Journal of International Money and Finance, 37, 113-134.

Agnello, L., Castro, V., Sousa, R.M. (2015). Booms, busts and normal times in the housing market. Journal of Business \& Economic Statistics, 33(1), 25-45.

Agnello, L., Castro, V., Hammoudeh, S., Sousa, R.M. (2017). Spillovers from the oil sector to the housing market cycle. Energy Economics, 61, 209-220.

Agnello, L., Castro, V., Sousa, R.M. (2018a). Economic activity, credit market conditions, and the housing market. Macroeconomic Dynamics, 22(7), 1769-1789.

Agnello, L., Castro, V., Sousa, R.M. (2018b). Systemic financial crises and the housing market cycle. Applied Economics Letters, 25(10), 724-729.

Agnello, L., Castro, V., Sousa, R.M. (2018c). The legacy and the tyranny of time: Exit and re-entry of sovereigns to international capital markets. Journal of Money, Credit and Banking, 50(8), 1969-1994.

Agnello, L., Castro, V., Sousa, R.M. (2018d). Financial markets' shutdown and re-access. Economic Inquiry, 56(1), 562-571.

Allison, P. (1982). Discrete-time methods for the analysis of event histories. Sociological Methodology, 13, 61-98. 
Almeida, H., Campello, M., Liu, C. (2005). The financial accelerator: Evidence from the international housing markets. Review of Finance, 10(3), 321-352.

Anderson, C.D., Capozza, D.R., Van Order, R. (2011). Deconstructing a mortgage meltdown: A methodology for decomposing underwriting quality. Journal of Money, Credit and Banking, 43(4), 609-631.

Anundsen, A.K., Gerdrup, K., Hansen, F., Kragh-Sorensen, K. (2016). Bubbles and crises: The role of house prices and credit. Journal of Applied Econometrics, 31(7), 1291-1311.

Arslan, Y. (2014). Interest rate fluctuations and equilibrium in the housing market. The BE Journal of Macroeconomics, 14(1), 173-204.

Arslan, Y., \& Upper, C. (2017). Macroprudential frameworks: implementation and effectiveness. BIS Papers, 94, 25-47.

Arslan, Y., Guler, B., Taskin, T. (2015a). Joint dynamics of house prices and foreclosures. Journal of Money, Credit and Banking, 47(S1), 133-169.

Arslan, Y., Kanik, B., Koksal, B. (2015b). Anticipated vs. unanticipated house price movements and transaction volume. Journal of Housing Economics, 28, 121-129.

Avdjiev, S., Binder, S., Sousa, R. (2017). External debt composition and domestic credit cycles. BIS Working Papers, no. 627.

Bailliu, J., Meh, C., Zhang, Y. (2015). Macroprudential rules and monetary policy when financial frictions matter. Economic Modelling, 50(C), 148-161.

Beck, N., Katz, J., Tucker, R. (1998). Taking time seriously: time-series-cross-section analysis with a binary dependent variable. American Journal of Political Science, 42, 1260-1288.

Bordo, M.D. (2003). Historical perspective on booms, busts and recessions. Chapter III When Bubbles Burst, IMF World Economic Outlook. (pp. 64-66): Washington.

Bordo, M.D., \& Jeanne, O. (2004). Boom-busts in asset prices, economic instability, and monetary policy. In Burdekin, R., \& Siklos, P. (Eds.) Deflation: Current and Historical Perspectives. Cambridge: Cambridge University Press.

Bordo, M.D., \& Landon-Lane, J. (2013). What explains house price booms?: History and empirical evidence. National Bureau of Economic Research. NBER Working Paper No. 19584.

Bordo, M.D., \& Landon-Lane, J. (2014). Does expansionary monetary policy cause asset price booms: Some historical and empirical evidence. In Bauducco, S., Christiano, L., Raddatz, C. (Eds.) Macroeconomic and Financial Stability: Challenges for Monetary Policy, Ed. 1, Vol. 19, Chapter 3, 61-116: Central Bank of Chile.

Bracke, P. (2013). How long do housing cycles last? a duration analysis from 19 OECD countries. Journal of Housing Economics, 22(3), 213-230.

Burnside, C., Eichenbaum, M., Rebelo, S. (2016). Understanding booms and busts in housing markets. Journal of Political Economy, 124(4), 1088-1147.

Calza, A., Monacelli, T., Stracca, L. (2013). Housing finance and monetary policy. Journal of the European Economic Association, 11(S1), 101-122.

Capozza, D.R., \& Van Order, R. (2011). The great surge in mortgage defaults 2006-2009: The comparative roles of economic conditions, underwriting and moral hazard. Journal of Housing Economics, 20(2), $141-151$.

Castro, V. (2010). The duration of economic expansions and recessions: More than duration dependence. Journal of Macroeconomics, 32(1), 347-365.

Castro, V. (2011). Can central banks' monetary policy be described by a linear (augmented) Taylor rule or by a nonlinear rule? Journal of Financial Stability, 27(4), 228-246.

Castro, V., \& Martins, R. (2013). Is there duration dependence in Portuguese local governments' tenure? European Journal of Political Economy, 31, 29-39.

Ceron, J.A., \& Suarez, J. (2006). Hot and cold housing markets: International evidence. Center for Economic and Policy Research. CEPR Discussion Paper No. 5411.

Cerutti, E., Dagher, J., Dell'Ariccia, G. (2015). Housing finance and real-estate booms:A cross-country perspective. Internationalmonetary Fund. IMFStaff Discussion Note No. 12.

Chang, K.-L., Chen, N.-K., Leung, C.K.Y. (2011). Monetary policy, term structure and asset return: Comparing REIT, housing and stock. Journal of Real Estate Finance and Economics, 43, 221-257.

Chen, N.-K., \& Leung, C.K.Y. (2008). Asset price spillover, collateral and crises: With an application to property market policy. Journal of Real Estate Finance and Economics, 37, 351-385.

Chen, N.-K., Cheng, H.-L., Ching-Sheng, M. (2014). Identifying and forecasting house prices: a macroeconomic perspective. Quantitative Finance, 14(12), 2105-2120.

Chiquier, L., \& Lea, M. (2009). Housing finance policy in emerging markets. Washington: World Bank. 
Cho, M. (2007). 180 years' evolution of the US mortgage banking system: Lessons for emerging mortgage markets. International Real Estate Review, 10(1), 171-212.

Cunningham, R., \& Kolet, I. (2011). Housing market cycles and duration dependence in the United States and Canada. Applied Economics, 43(5), 569-586.

Diamond, D.W., \& Lea, M.J. (1992). The decline of special circuits in developed country housing finance. Housing Policy Debate, 3(3), 747-777.

Diamond, D.W., \& Rajan, R.G. (2009). The credit crisis: Conjectures about causes and remedies. American Economic Review, 99, 606-610.

Diebold, F., \& Rudebusch, G. (1991). Turning point prediction with the composite leading index: an ex ante analysis. In Lahiri, K., \& Moore, G. (Eds.) Leading economic indicators: New approaches and forecasting records. Cambridge: University Press.

Dufrénot, G., \& Malik, S. (2012). The changing role of house price dynamics over the business cycle. Economic Modelling, 29(5), 1960-1967.

Dynan, K.E., Elmendorf, D.W., Sichel, D. (2006). Can financial innovation help to explain the reduced volatility of economic activity? Journal of Monetary Economics, 53, 123-150.

ECB. (2003). Structural factors in the EU housing markets. March 12. Frankfurt: European Central Bank.

Ellis, L. (2008). The housing meltdown: Why did it happen in the United States? Bank for International Settlements, BIS Working Paper, no. 259.

Englund, P., \& Ioannides, Y.M. (1997). House price dynamics: an international empirical perspective. Journal of Housing Economics, 6, 119-136.

Falagiarda, M., \& Saia, A. (2017). Credit, endogenous collateral and risky assets: a DSGE model. International Review of Economics \& Finance, 49(C), 125-148.

Fuster, A., Plosser, M., Schnabl, P., Vickery, J. (2018). The role of technology in mortgage lending. Federal Reserve Bank of New York, Staff Report no. 836.

Gattini, L., \& Hiebert, P. (2010). Forecasting and assessing euro area house prices through the lens of key fundamentals. European Central Bank. ECBWorking Paper No. 1249.

Gelain, P., \& Ilbas, P. (2017). Monetary and macroprudential policies in an estimated model with financial intermediation. Journal of Economic Dynamics and Control, 78(C), 164-189.

Girouard, N., \& Blöndal, S. (2001). House prices and economic activity. Organisation for Economic CoOperation and Development. OECD Economics Department Working Paper No. 279.

Granville, B., \& Mallick, S.K. (2009). Monetary and financial stability in the euro area: procyclicality versus trade-off. Journal of International Financial Markets. Institutions and Money, 19, 662-674.

Green, R., \& Wachter, S.M. (2005). The American mortgage in historical and international context. Journal of Economic Perspectives, 19(4), 93-114.

Hiebert, P., \& Roma, M. (2010). Relative house price dynamics across euro area and US cities. Convergence or divergence? European Central Bank. ECBWorking Paper No. 1206.

Iacoviello, M. (2005). House prices, borrowing constraints, and monetary policy in the business cycle. American Economic Review, 95, 739-764.

Igan, D., Kabundi, A., De Simone, F.N., Pinheiro, F., Tamirisa, N. (2011). Housing, credit and real activity cycles: Characteristics and comovement. Journal of Housing Economics, 20(3), 210-231.

Igan, D., \& Loungani, P. (2012). Global housing cycles. International Monetary Fund. IMF Working Paper No. 217.

IMF (2008). The changing housing cycle and its implications for monetary policy. IMF World Economic Outlook, April, Chapter 3, 103-130. International Monetary Fund:Washington, District of Columbia (USA).

IMF. (2009). Debt bias and other distortions: Crisis-related issues in tax policy. Washington: International Monetary Fund, Fiscal Affairs Department.

IMF. (2011). Global financial stability report - Durable financial stability: Getting there from here. Washington: International Monetary Fund.

Jenkins, S. (1995). Easy estimation methods for discrete-time duration models. Oxford Bulletin of Economics and Statistics, 57, 129-138.

Jenkins, S. (2005). Survival analysis. University of Essex. Unpublished manuscript. Available at: https:// www.iser.essex.ac.uk/files/teaching/stephenj/ec968/pdfs/ec9681notesv6.pdf.

Kannan, P., Rabanal, P., Scott, A. (2012). Monetary and macroprudential policy rules in a model with house price booms. B.E. Journal of Macroeconomics, 12(1), 1-44.

Kelly, R., McCann, F., O’Toole, C. (2017). Credit conditions, macroprudential policy and house prices. European Systemic Risk Board. ESRB Working Paper no. 36. 
Kiefer, N. (1988). Economic duration data and hazard functions. Journal of Economic Literature, 26, $646-679$.

Leung, C.K.Y. (2004). Macroeconomics and housing: a review of the literature. Journal of Housing Economics, 13, 249-267.

Leung, C.K.Y. (2007). Equilibrium correlations of asset price and return. Journal of Real Estate Finance and Economics, 34(2), 233-256.

Leung, C.K.Y. (2014). Error correction dynamics of house prices: an equilibrium benchmark. Journal of Housing Economics, 25(C), 75-95.

Leung, C.K.Y., \& Feng, D. (2005). What drives the property price-trading volume correlation? Evidence from a commercial real estate market. Journal of Real Estate Finance and Economics, 31(2), 241-255.

Leung, C.K.Y., \& Ng, J.C.Y. (2018). Macro aspects of housing. Federal Reserve Bank of Dallas, Globalization and Monetary Policy Institute Working Paper no. 340.

Leung, C.K.Y., Lau, G.C.K., Leong, Y.C.F. (2002). Testing alternative theories of the property pricetrading volume correlation. Journal of Real Estate Research, 23(3), 253-263.

Loungani, P. (2010a). Housing markets: More room to fall? IMFFinance \&Development.

Loungani, P. (2010b). Q\&a: Seven questions about house price cycles. IMFResearch Bulletin, 11(1), 6-9.

Mallick, S.K., \& Mohsin, M. (2010). On the real effects of inflation in open economies: theory and empirics. Empirical Economics, 39(3), 643-673.

Mallick, S.K., \& Mohsin, M. (2016). Macroeconomic effects of inflationary shocks with durable and non-durable consumption. Open Economies Review, 27(5), 895-921.

OECD. (2011). Housing and the economy: Policies for renovation. Economic Policy Reforms 2011 - Going for growth. Paris: Organization of Economic Cooperation and Development.

Ortalo-Magne, F., \& Rady, S. (2006). Housing market dynamics: on the contribution of income shocks and credit constraints. Review of Economic Studies, 73, 459-485.

Peek, J., \& Wilcox, J. (2006). Housing, credit constraints, and macro stability: The secondary mortgage market and reduced cyclicality of residential investment. American Economic Review, 96(2), 135-140.

Poghosyan, T. (2016). Can property taxes reduce house price volatility? Evidence from U.S. regions. International Monetary Fund. IMFWorking Paper No. 216.

Prentice, R., \& Gloeckler, L. (1978). Regression analysis of grouped survival data with application to the breast cancer data. Biometrics, 34, 57-67.

Rajan, R.G. (2005). Has financial development made the world riskier? The Greenspan era: Lessons for the future. Federal Reserve Bank of Kansas City, Jackson Hole Symposium (pp. 313-369).

Rubio, M., \& Carrasco-Gallego, J.A. (2014). Macroprudential and monetary policies: Implications for financial stability and welfare. Journal of Banking \& Finance, 49(C), 326-336.

Rubio, M., \& Carrasco-Gallego, J.A. (2017). Spain and the crisis: Housing prices, credit and macroprudential policies. Singapore Economic Review, 62(1), 109-133.

Sá, F. (2016). The effect of foreign investors on local housing markets:Evidence from the UK. CEPRWorking Paper no. 11658.

Sá, F., \& Wieladek, T. (2015). Capital inflows and the US housing boom. Journal of Money. Credit and Banking, 47(S1), 221-256.

Sá, F., Towbin, P., Wieladek, T. (2014). Capital flows, financial structure and housing booms. Journal of the European Economic Association, 12(2), 522-546.

Sousa, R.M. (2010a). Consumption, (dis)aggregate wealth and asset returns. Journal of Empirical Finance, $17(4), 606-622$.

Sousa, R.M. (2010b). Housing wealth, financial wealth, money demand and policy rule: Evidence from the euro area. The North American Journal of Economics and Finance, 21(1), 88-105.

Tsatsaronis, K., \& Zhu, H. (2004). What drives housing price dynamics:cross-country evidence. BIS Quarterly Review.

Publisher's Note Springer Nature remains neutral with regard to jurisdictional claims in published maps and institutional affiliations. 


\title{
Affiliations
}

\section{Luca Agnello ${ }^{1}$ - Vitor Castro ${ }^{2,3}$ (1) Ricardo M. Sousa ${ }^{4,5}$}

\author{
Luca Agnello \\ luca.agnello01@unipa.it
}

Ricardo M. Sousa

rjsousa@eeg.uminho.pt; rjsousa@alumni.lse.ac.uk

1 Department of Economics, Business and Statistics (SEAS), University of Palermo, Viale delle Scienze, 90128 Palermo, Italy

2 School of Business and Economics, Loughborough University, Loughborough, Leicestershire LE11 3TU, UK

3 Economic Policies Research Unit (NIPE), University of Minho, Campus of Gualtar, 4710-057 Braga, Portugal

4 Department of Economics and Economic Policies Research Unit (NIPE), University of Minho, Campus of Gualtar, 4710-057 Braga, Portugal

5 London School of Economics and Political Science, LSE Alumni Association, Houghton Street, London WC2 2AE, UK 